\title{
MATRIMONIO Y DISCAPACIDAD ${ }^{1}$
}

\author{
Marriage and disability
}

\author{
CRISTINA GUILARTE MARTÍN-CALERO \\ Universidad de Valladolid \\ cristina.guilarte@uva.es
}

Cómo citar/Citation

Guilarte Martín-Calero, C. (2018).

Matrimonio y discapacidad.

Derecho Privado y Constitución, 32, 55-94.

doi: https://doi.org/10.18042/cepc/dpc.32.02

Recepción: 30/04/2018. Aceptación tras revisión: 05/06/2018. Publicación: 22/06/2018.

\section{Resumen}

En el presente trabajo se estudia el ius connubii de las personas con discapaci$\mathrm{dad}$, reconocido en distintos textos internacionales y en particular en la Convención de Nueva York relativa a los derechos de las personas con discapacidad. Se analiza con detalle la nueva redacción del art. 56 del Código Civil dada por la Ley 4/2017, de 28 de julio, a fin de determinar si las cautelas legales introducidas en la regulación española constituyen una discriminación por razón de discapacidad prohibida en el art. 2 de la Convención de Nueva York.

\section{Palabras clave}

Matrimonio; discapacidad; capacidad jurídica; consentimiento matrimonial, ius connubii.

1 El presente trabajo se ha realizado en el marco del proyecto de investigación DER201569120-R (MINECO-FEDER) «La nueva protección jurídica de las personas vulnerables». 


\section{Abstract}

This paper studies the ius connubii of persons with disabilities, recognized in various international texts and in particular in the New York Convention on the Rights of Persons with Disabilities. The new wording of art. 56 of the Civil Code given by Law 4/2017 of 28 July is analysed in detail in order to determine whether the legal precautions introduced in the Spanish regulations constitute discrimination on grounds of disability prohibited by art. 2 of the New York Convention.

\section{Keywords}

Marriage; disability, legal capacity; marriage consent, ius connubii. 


\section{SUMARIO}

I. ALGUNAS CONSIDERACIONES INTRODUCTORIAS EN TORNO A LA DISCAPACIDAD. II. EL DERECHO A CONTRAER MATRIMONIO DE LAS PERSONAS CON DISCAPACIDAD. III. EL TRATAMIENTO DEL MATRIMONIO DE LAS PERSONAS CON DISCAPACIDAD EN LAS DISTINTAS REFORMAS DEL CÓDIGO CIVIL: 1. EI Código Civil de 1989. 2. Su regulación en la Ley de 7 de julio de 1981: el artículo 56.2 del Código Civil: 2.1. El control inicial de la capacidad para consentir válidamente: la doctrina de la DGRN. 2.2. El control ex post de la capacidad para consentir: la nulidad matrimonial. 3. La Ley 15/2015, de 2 de julio, de Jurisdicción Voluntaria. 4. La Ley 4/2017, de 28 de junio, de Modificación de la Ley 15/2015, de 2 de julio, de la Jurisdicción Voluntaria. IV. EL CARÁCTER DISCRIMINATORIO DE LA REGLA APLICABLE A LAS PERSONAS CON DISCAPACIDAD: 1. El modelo belga: la autorización judicial previa (dictamen médico e informe social). 2. El modelo francés: la autorización del matrimonio por un tercero (autorización del curador y, en su defecto, del juez de tutelas). 3. El modelo argentino: la dispensa judicial. 4. El modelo suizo: control de oficio del encargado del Registro Civil. V. CONCLUSIONES. BIBLIOGRAFía.

\section{ALGUNAS CONSIDERACIONES INTRODUCTORIAS EN TORNO A LA DISCAPACIDAD}

El análisis del matrimonio de las personas con discapacidad no se puede abordar sin tener muy presente el cambio radical introducido por la Convención Internacional sobre los Derechos de las Personas con Discapacidad, aprobada por la Organización de Naciones Unidas el 13 de diciembre de 2006, ratificada por España el 23 de noviembre de 2007 y por la Unión Europea el 23 de noviembre de 2010. Esta convención ha traído consigo un nuevo prisma desde el que afrontar la situación en que se encuentran las personas con discapacidad física, mental, intelectual o sensorial: la discapacidad es una cuestión de derechos humanos.

El propósito de la convención, tal y como se desprende de su artículo primero, es promover, proteger y asegurar el goce pleno y en condiciones de igualdad de todos los derechos humanos y libertades fundamentales por todas las personas con discapacidad, y promover el respeto de su dignidad inherente, 
amparando el texto a todas aquellas personas que tengan deficiencias físicas, mentales, intelectuales o sensoriales a largo plazo y que, al interactuar con diversas barreras, puedan impedir su participación plena y efectiva en sociedad, en igualdad de condiciones con las demás. Además, el respeto de la dignidad inherente, la autonomía individual, incluida la libertad de tomar las propias decisiones, y la independencia personal se erigen, junto con otros, en principios fundamentales de la citada convención.

Por otra parte, se impone a los Estados partes, en el art. 12, la obligación de adoptar las medidas pertinentes para proporcionar el acceso de las personas con discapacidad al apoyo que puedan necesitar en el ejercicio de su capacidad jurídica, medidas que deberán ser proporcionales al grado en que afecten a los derechos e intereses de las personas, adaptadas a sus circunstancias y de carácter temporal y, en todo caso, deberán respetar los derechos, la voluntad y las preferencias de la persona y garantizar que no haya conflicto de intereses ni influencia debida.

Se señala, además, como cambio radical el abandono de un modelo médico rehabilitador y la adopción de un modelo social que concibe la discapacidad como una «situación derivada de estructuras y condicionamientos sociales» y no como un rasgo personal derivado de la existencia de deficiencias físicas o psíquicas (De Asís Roig, 2013: 16); así, el segundo inciso del art. 1 se refiere a las barreras que «puedan impedir su participación plena y efectiva en la sociedad, en igualdad de condiciones con las» demás.

Aceptada, por supuesto, la importancia de este cambio, resaltado por todos los estudiosos de la convención ${ }^{2}$, por el legislador ${ }^{3}$ y el Tribunal Supremo $^{4}$, debe reconocerse asimismo su influencia decisiva en la nueva configuración de la capacidad jurídica regulada en el art. 12 CNY que obliga a los Estados partes a rediseñar los sistemas de incapacidad y el ejercicio

2 Véase por todos Palacios (2008); puede verse una crítica del llamado modelo social en Álvarez Lata y Seoane (2010: 15); igualmente, Martínez de Aguirre (2014: 37).

3 Véase el preámbulo de la Ley 26/2011, de 1 de Agosto, de adaptación normativa a la Convención Internacional sobre los Derechos de las Personas con Discapacidad.

4 El TS recoge la tesis del modelo social de la discapacidad, por ejemplo, en STS de 30 de mayo de 2012, y se reitera en la de 7 de julio de 2014: «La Convención sustituye el modelo médico de la discapacidad por un modelo social y de derecho humano que al interactuar con diversas barreras, puede impedir la participación plena y efectiva del incapacitado en la sociedad, en igualdad de condiciones con las demás. Estamos ante una nueva realidad legal y judicial y uno de los retos de la Convención será el cambio de las actitudes hacia estas personas para lograr que los objetivos del Convenio se conviertan en realidad». 
de los derechos cuya titularidad ostenta la persona con discapacidad ${ }^{5}$. Esta perspectiva resulta de indudable importancia para el presente estudio toda vez que el art. 23, que reconoce el derecho a contraer matrimonio por las personas con discapacidad, debe considerarse una especificación de lo dispuesto en aquel precepto en lo que respecta a la vida familiar de las personas con discapacidad.

$\mathrm{El}$ art. 12 alerta con carácter general contra aquellos sistemas y prácticas que excluyen a la persona con discapacidad de la toma de decisiones sobre las cuestiones que les afectan, bien en su esfera personal (tratamientos médicos, lugar de residencia...), bien en su esfera patrimonial (propiedad, herencia, control de asuntos económicos, préstamos bancarios, hipotecas y otras modalidades de crédito financiero) y que impiden, directa o indirectamente, el ejercicio de sus derechos fundamentales.

Por su parte, el art. 23, cuando se refiere al respeto a la vida familiar de las personas con discapacidad, proscribe, con carácter general, la discriminación en las cuestiones relacionadas con el matrimonio, la familia, la paternidad y las relaciones personales y, a continuación, impone a los Estados miembros obligaciones de carácter positivo que tiendan a eliminar aquella discriminación y posibiliten el pleno disfrute de los derechos que se integran en el concepto de vida familiar (derecho a contraer matrimonio, a fundar una familia, a las relaciones personales de carácter familiar...).

Así pues, en este estudio deberán tenerse presentes en todo momento los postulados de la Convención de Nueva York (prohibición de discriminación, respeto de la dignidad inherente, la autonomía individual, incluida la libertad de tomar las propias decisiones, la independencia personal) y, en particular, las obligaciones positivas que se imponen al Estado español en los arts. 12 y 23.

\section{EL DERECHO A CONTRAER MATRIMONIO DE LAS PERSONAS CON DISCAPACIDAD}

El derecho a contraer matrimonio y fundar una familia se reconoce al hombre y la mujer a partir de la edad núbil en todos los instrumentos internacionales de derechos humanos; así, en el art. 16 de la Declaración Universal de Derechos Humanos de 1948, en el art. 23.2 del Pacto Internacional de

5 Sobre su interpretación y alcance puede verse la observación núm. 1 ( $11^{\circ}$ periodo de sesiones, 31 de marzo a 11 de abril de 2014) relativa al art.12 de la Convención de Nueva York: «Igual reconocimiento como persona ante la ley»; véase asimismo el exhaustivo estudio de Bariffi (2014). 
Derechos Civiles y Políticos y en el art. 12 del Convenio Europeo para la Protección de los Derechos Humanos y las Libertades Fundamentales que remite, además, a las leyes nacionales que regulan su ejercicio (capacidad, prohibiciones y exigencias formales). A pesar de esta remisión, el derecho garantizado por el art. 12 no es el derecho a contraer matrimonio tal y como está concebido en las legislaciones nacionales, sino el derecho a contraer matrimonio perfilado por el TEDH en su interpretación del art. 12 que, en síntesis, y por lo que aquí interesa, se condensa en el asunto Frasik contra Polonia; allí se afirma que las limitaciones o prohibiciones impuestas por los Estados parte «no pueden reducirlo o restringirlo hasta el punto de afectar a su propia sustancia», por tanto, no pueden implicar, en la práctica, la prohibición del ejercicio del derecho ${ }^{6}$ o la exclusión automática de un grupo determinado, como por ejemplo las personas que se encuentran en prisión ${ }^{7}$. Además, para luchar contra los matrimonios forzados y proteger a la infancia, no se considera vulnerado el derecho a contraer matrimonio por el establecimiento de una edad núbil legal superior a la exigida, por ejemplo, por la religión de los novios ${ }^{8} \mathrm{o}$ por el impedimento de ligamen (en prevención del delito de bigamia) o del parentesco por afinidad?.

Es importante subrayar, tal y como apunta el TEDH, que el derecho reconocido en el art. $12 \mathrm{CEDH}$ no prevé ningún motivo que justifique la injerencia del Estado, como sucede en el art. 8.2 CEDH (injerencia prevista en la ley y necesaria en una sociedad democrática para proteger la salud, la moral o la protección de los derechos y libertades de terceros), de suerte que, respecto del derecho a contraer matrimonio y en atención al margen de apreciación reconocido a los Estados, el control de convencionalidad solo deberá verificar si la injerencia es arbitraria o desproporcionada.

Por su parte, la Convención de Nueva York en el art. 23.1.a) exige que se «reconozca el derecho de todas las personas con discapacidad en edad de contraer matrimonio, a casarse y fundar una familia sobre la base del consentimiento libre y pleno de los futuros cónyuges». Del tenor literal del precepto se colige que solo la edad y el consentimiento libre y pleno de los futuros cónyuges son requisitos del matrimonio de las personas con discapacidad, a los

\footnotetext{
STEDH de 11 de julio de 2002, asunto Goodwin e Y c. Reino Unido.

7 SSTEDH de 5 de enero de 2010, asunto Frasik c. Polonia y asunto Jaremowicz c. Polonia.

8 STEDH de 8 de diciembre de 2015, asunto ZH y RH c. Suiza.

9 STEDH de 5 de enero de 2010, asunto Frasik c. Polonia. En cambio, en la STEDH, de 13 de septiembre de 2005, asunto B.L. c. Reino Unido, condena el impedimento matrimonial que prohíbe el matrimonio entre el suegro y la nuera.
} 
que naturalmente habrán de sumarse las condiciones de ejercicio previstas con carácter general en la legislación nacional (impedimentos, formalidades, publicidad...) y que no deberían contener, en principio, alusiones a las personas con discapacidad. Si se combina la interpretación del TEDH y lo dispuesto en la CNY, la legislación nacional no puede establecer normas limitativas o prohibitivas del derecho a contraer matrimonio de las personas con discapacidad que sean arbitrarias o desproporcionadas.

A la luz de esta consideración, confrontaremos el tratamiento que el derecho español dispensa al matrimonio de las personas con discapacidad para determinar su adecuación a los textos supranacionales que nos obligan ${ }^{10}$.

10 Respecto de las exigencias establecidas por las distintas leyes autonómicas para la constitución de las parejas de hecho (véase, ampliamente, De Amunátegui, 2017: 868-1047), con carácter general, las que tienen competencia en materia civil requieren bien la mayoría de edad (Aragón, art. 303 CDFA), bien la emancipación (Cataluña — art. 234-2 Cccat—, Navarra —art. 2.1 de la Ley Foral 6/2000, de 3 de julio, para la Igualdad Jurídica de las parejas estables de Navarra—y Baleares — art. 2.1.de la Ley 18/2001, de 19 de diciembre, de Parejas Estables); tan solo Galicia (DA $3^{a}$ de la Ley 2/2006, de 14 de junio, de Derecho civil de Galicia) y País Vasco (art. 2 de la Ley 2/2003, de 7 de mayo, reguladora de las parejas de hecho) exigen la plena capacidad, de suerte que, quienes pueden contraer matrimonio conforme a la regulación estatal, no pueden ser pareja de hecho en estas comunidades autónomas, lo que constituye una discriminación por razón de discapacidad prohibida en el art. 2 CNY. Las demás leyes autonómicas mantienen en general la exigencia de la emancipación (Andalucía —art. 3.2.a) de la Ley 5/2002, de 16 de diciembre, de parejas de hecho de Andalucía_, Asturias — art. 3.1 de la Ley 4/2002, de 23 de mayo, que regula las parejas estables_, Extremadura — art. 2.1 de la Ley 5/2003, de 20 de marzo, de parejas de hecho de Extremadura-, Valencia —art. 4.1.a) de la Ley 5/2012, de 15 de octubre, de uniones de hecho formalizadas de la Comunidad de Valencia), aunque también se excluye, en algún caso, a la persona con discapacidad (Cantabria — art. 4.4.f) de la Ley 1/2005, de 16 de mayo, de parejas de hecho de Cantabria-, Canarias —art. 2.1.f) de la Ley 5/2003, de 6 de marzo, de parejas de hecho de Canarias_, Madrid —art. 2.1.a) de la Ley 11/2001, de 19 de diciembre, de uniones de hecho de la Comunidad de Madrid-). E incluso se veda el simple acceso al Registro de parejas no casadas a quienes estén «incapacitados» (Castilla-León —art. 3.1.e) del Decreto 117/2002, de 24 de octubre, que crea el Registro de Uniones de Castilla y León-, Castilla-La Mancha -art.3.1. del Decreto $124 / 2000$, de 11 de julio, regulador de la creación y régimen de funcionamiento del Registro de parejas de hecho de la Comunidad Autónoma de Castilla-La Manchay La Rioja - art. 3.1.g) del Decreto 30/2010, de 14 de mayo, creador del Registro de Parejas de Hecho). Estas previsiones normativas deberán ser revisadas a la luz de la Convención de Nueva York y, en particular, de su art. 12. 


\section{EL TRATAMIENTO DEL MATRIMONIO DE LAS PERSONAS CON DISCAPACIDAD EN LAS DISTINTAS REFORMAS DEL CÓDIGO CIVIL}

\section{EL CÓDIGO CIVIL DE 1989}

En la redacción originaria del Código Civil se prohibía contraer matrimonio «a los que no estuvieren en el pleno ejercicio de su razón al tiempo de contraer matrimonio» (art. 83.2) y, de celebrarse, se abría el cauce de la nulidad en el art. $101.1^{\circ} \mathrm{CC}$; no se excluía al incapacitado ni en sede matrimonial ni en sede tutelar, de suerte que, en principio, debiera entenderse que esta referencia se hace al «incapaz» incapacitado o no y de admitirse el intervalo lúcido, como propugnaba la doctrina mayoritaria, aunque con vacilaciones, se abre el matrimonio a quien «en el momento de contraer» está en pleno uso de su razón. La opinión favorable a la posibilidad de contraer matrimonio durante un intervalo lúcido fue defendida por De Castro (1984: 321), sobre la base de las siguientes razones:

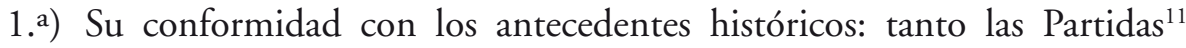
como la Ley de Registro Civil ${ }^{12}$ así lo admitían, haciéndose una referencia expresa en esta última: «Al momento de la celebración del matrimonio y solamente a él hay que atender para saber si el individuo tiene o no aptitud para contraerlo. El demente habitual no carecerá de ella en un momento de lucidez, ni el hombre sano la tendrá en un instante de locura» ${ }^{13}$.

2. a) Las formalidades previas del matrimonio pueden servir de garantía relativa de que existe la capacidad natural del contrayente.

3. a) El matrimonio puede ser un medio para cumplir sagrados deberes y el derecho nunca debe ser obstáculo para tal cumplimiento, en especial para legitimar a la prole.

4.a) Lo terminante de su redacción.

No se contemplan entre las funciones del tutor (arts. 261 y ss.) ni del Consejo de Familia (arts. 293 y ss.) autorizar ni aconsejar sobre la celebración

11 P. 4, 2, 6: «Si alguno fuese loco e después tornase en su acuerdo, si en aquélla sazón que fuese en su memoria consintiese en el casamiento, valdría».

12 Art. 4.2\%: «Estar en pleno uso de su razón al tiempo de celebrar el matrimonio».

13 Véase la exposición de motivos de la Ley de Matrimonio Civil de 1870. 
del matrimonio del incapacitado ${ }^{14}$, de suerte que, a esta, únicamente se le exige la concurrencia de la capacidad natural en el momento de la celebración ${ }^{15}$, que no puede ser dispensada o convalidada, como ocurre respecto de la edad, el error, la violencia, la intimidación o la falta de libertad en el supuesto del rapto (art. 102 CC), al carecer de su más esencial requisito: la falta de consentimiento matrimonial determina la nulidad del matrimonio.

Ahora bien, a pesar de admitirse la posibilidad de contraer matrimonio en intervalo lúcido, lo cierto es que la deficiencia psíquica se configuraba como incapacidad para contraer matrimonio ${ }^{16}$.

Este esquema originario que vedaba el matrimonio a quien no goza de la capacidad natural al tiempo de contraerlo se va a mantener, como veremos, hasta nuestros días, donde la capacidad para prestar el consentimiento no se anuda a la capacidad legal sino a la capacidad natural y donde, con mejor técnica jurídica, para estos casos, se articula un mecanismo de verificación ad casum, y ello en perfecta sintonía con los mandatos explicitados en los textos internacionales de referencia.

\section{SU REGULACIÓN EN LA LEY DE 7 DE JULIO DE 1981: EL ARTíCULO 56.2 DEL CÓDIGO CIVIL}

La Constitución Española, en su art. 32, reconoce el derecho a contraer matrimonio, sin referirse a él de forma muy precisa (Salvador Coderch, 1984: 121) y remitiéndose a la ley para la regulación concreta de los requisitos de validez del matrimonio que se desarrollan en la Ley de 7 de julio de 1981; esta ley, que reforma en profundidad la institución matrimonial, aunque en línea con los antecedentes históricos apuntados, va más allá y se limita a

14 Previsión que sí se recoge respecto del menor de edad que ha de obtener licencia del Consejo de Familia si no existen las personas designadas legalmente para otorgarla (art. $46 \mathrm{CC}$ ); el consejo favorable del padre y, en su defecto, de la madre se exige únicamente respecto del mayor de edad (art. 47) y su falta solo comportaba el retraso temporal de la celebración (tres meses).

15 Respecto del matrimonio canónico se exigía la expresa autorización del ordinario para la celebración del matrimonio del incapacitado por enfermedad mental (art.17, Instrucción sobre la celebración del matrimonio de la Santa Congregación para la disciplina de los Sacramentos de 1 de julio de 1929).

16 También en el derecho canónico se reputan incapaces para contraer matrimonio en el Canon 1095: «1. Quienes carecen de suficiente uso de razón; 2. Quienes tienen un grave defecto de discreción de juicio acerca de los derechos y deberes esenciales del matrimonio que mutuamente se han de dar y aceptar; 3. Quienes no pueden asumir las obligaciones esenciales del matrimonio por causas de naturaleza psíquica». 
prohibir el matrimonio de los menores de edad no emancipados y de los que se hallen ligados por vínculo matrimonial previo (art. $46 \mathrm{CC}$ ), de manera que la referencia a las personas con discapacidad mental o intelectual no se encuentra en las condiciones de acceso al matrimonio, sino en la tramitación del expediente matrimonial que acoge una regla procedimental especial que permite al instructor asegurarse de la aptitud para consentir de los futuros contrayentes; por tanto, la aptitud para contraer válidamente matrimonio, a tenor de lo establecido en el art. 45 («no hay matrimonio sin consentimiento matrimonial») y el art. $73.1^{\circ}$ («es nulo cualquiera que sea su celebración: el matrimonio celebrado sin consentimiento matrimonial»).

Aunque en la regulación anterior hemos visto que se exigía la capacidad natural, igual que acontece en la regulación actual, lo cierto es que se produce un cambio fundamental en la configuración de la capacidad para contraer matrimonio, toda vez que solo la edad y el ligamen previo aparecen como «prohibiciones» $\mathrm{o}$ «incapacidades», cuando antes se incluía también aquí la referencia a la discapacidad ${ }^{17}$; así que quienes antes quedaban excluidos a no ser que se probara la capacidad natural hoy tienen capacidad para contraer a no ser que se acredite su falta de capacidad natural en la instrucción del expediente matrimonial. La regla hoy es la capacidad para contraer matrimonio y la excepción es la ineptitud para contraer matrimonio; este carácter excepcional exige, por tanto, una interpretación restrictiva, respetuosa con el ius nubendi y el favor matrimonii ${ }^{18}$.

Si esta regulación se contrasta con los dictados de las normas internacionales se observa que el derecho a contraer matrimonio solo queda vedado, con

17 Así se preveía también en el Proyecto de ley de modificación de la regulación del matrimonio en el Código civil y se determina el procedimiento a seguir en las causas de nulidad, separación y divorcio (BOC, núm. 193, de 13 de marzo de 1980), que en su art. 46.2 establecía que no pueden contraer matrimonio «los que no estén en el ejercicio de su razón»; esta previsión desaparece en el Informe de la Ponencia.

En este sentido la DGRN, en su Resolución de 6 de mayo de 2005, sostiene que «si se tienen en cuenta la presunción general de buena fe y que el ius nubendi, como derecho fundamental de la persona no debe ser coartado, postergado o denegado más que cuando exista certeza racional absoluta del obstáculo legal que vicie de nulidad el matrimonio pretendido, ha de ser preferible, aun en casos de duda, no poner trabas a la celebración del enlace. Como expresó en un supuesto similar la Resolución de 9-2a de octubre de 1993, "ante la opción de no autorizar un matrimonio que eventualmente sea declarado nulo o de coartar el ius connubii, este Centro ha de elegir la primera alternativa”". Igualmente, la RDGRN de 12 de marzo de 1994 afirma que «en caso de duda, han de prevalecer los principios constitucionales del libre desarrollo de la personalidad y del ejercicio de los derechos fundamentales». 
carácter general, a quienes no han alcanzado la edad núbil (fijada en los 16 años y con posibilidad de dispensa a partir de los 14) y a quienes mantienen vínculo matrimonial previo; por tanto en línea con lo allí dispuesto.

Ahora bien, a lo largo de la tramitación del expediente matrimonial el instructor debe asegurarse de que existe consentimiento matrimonial y, para ello, el legislador de 1981 articula un mecanismo que permita verificar la concurrencia de capacidad natural en el momento concreto y ello con independencia de la situación de incapacitación o no incapacitación de los futuros contrayentes ${ }^{19}:$ «Si alguno de los contrayentes estuviere afectado por

19 Como apunta Puig Ferriol (1984: 255), en el caso de que la persona haya sido previamente incapacitada, la presunción de incapacidad que rige a partir de la firmeza de la sentencia exige el dictamen médico en todo caso; y si no hay incapacitación solo si en la instrucción del expediente se observa en alguno de los contrayentes anomalías que puedan afectar a la prestación del consentimiento. En el mismo sentido, Gete-Alonso (1984: 371). Igualmente, la RDGRN de 27 de julio de 1993 afirma que la autorización del matrimonio de quien está incapacitado totalmente ha de resolverse a la luz de dos consideraciones: «La primera es que se trata de una persona que por sentencia previa ha sido declarada en situación incapacidad total, de modo que la presunción general de capacidad que ha de apreciarse respecto de todo mayor de edad, está aquí desvirtuada y ha de presumirse, por el contrario, que el afectado carece de aptitud para consentir cualquier acto jurídico. La segunda consideración es la de que si, pese a ese estado civil declarado judicialmente, todavía cabe que el contrayente afectado por deficiencias o anomalías psíquicas sea autorizado para contraer matrimonio, para ello es preciso que en el expediente previo recaiga el oportuno dictamen médico y que, a la vista de él, el Encargado, asistido del Secretario, se cerciore de la inexistencia de ese obstáculo legal en la audiencia personal, reservada y por separado, prevista en el art. 246 RRc»; la RDGRN de 2 de junio de 1999 afirma que de la incapacitación del contrayente «se desprende que hay una presunción de incapacidad natural que requeriría una convincente prueba en contrario que acreditara la aptitud para prestar el consentimiento matrimonial, exigiéndose entonces el dictamen médico tanto en los casos de incapacidad natural o de hecho para prestar el consentimiento como en los casos en los que la incapacitación haya sido declarada judicialmente». En parecidos términos se expresan las RRDGRN de 24 de marzo de 1994 y 23 de octubre de 1996, que señalan que "pese a la presunción general de capacidad de los mayores de edad para todos los actos de la vida civil (art. 322 Cc), esta presunción está sujeta a excepciones en las que debe comprobarse previamente la capacidad natural de la persona para prestar consentimiento a un acto determinado. Así sucede en el matrimonio porque el art. 56 del Código civil, después de señalar que en el expediente previo al matrimonio en forma civil debe acreditarse por los contrayentes que reúnen los requisitos de capacidad establecidos en este Código, añade en su segundo párrafo que "si alguno de los contrayentes estuviere afectado por deficiencias o anomalías psí- 
deficiencias o anomalías psíquicas, se exigirá dictamen médico sobre aptitud para prestar el consentimiento ${ }^{20}$.

Este dictamen médico tiene por único objeto acreditar si el contrayente afectado por las anomalías psíquicas «tiene conciencia de la naturaleza y los efectos del matrimonio y del estado matrimonial $\aleph^{21}$, por tanto, de las obligaciones que el Código impone a ambos cónyuges en condiciones de igualdad ${ }^{22}$.

Como señala la RDGRN de 30 de junio de 2005, «ha sido voluntad del legislador tomar como parámetro para apreciar la aptitud para acceder al

quicas, se exigirá dictamen médico sobre su aptitud para prestar el consentimiento". Este precepto es aplicable tanto a los casos de previa incapacitación judicial como a aquellos en los que ésta aún no se ha pronunciado». En el mismo sentido, la reciente STS de 8 de noviembre de 2017 afirma: «En ausencia de norma expresa que permita privar «in genere» de la capacidad para contraer matrimonio, debe considerarse que las personas con enfermedades mentales o deficiencias sí pueden contraerlo cuando puedan prestar válido consentimiento matrimonial, cuando posean la capacidad natural de entender y querer la unión matrimonial, lo que es posible tanto si la persona está incapacitada (lo confirma el art. 171.4. ${ }^{\circ} \mathrm{CC}$ ) como cuando, sin estarlo, adolezca de alguna deficiencia psíquica. Así resulta del tenor del art. 56 CC vigente que exige que quienes deseen contraer matrimonio acrediten previamente que reúnen los requisitos de capacidad exigidos y, si alguno de los contrayentes está afectado por anomalías psíquicas, se exige dictamen médico sobre su aptitud para prestar consentimiento».

20 La comprobación de la madurez de juicio ad casum se predicaba igualmente del menor de 16 y mayor de 14 que podía obtener dispensa (art. $48 \mathrm{CC}$ ), previa audiencia del menor y de sus padres o guardadores.

21 Véase Puig Ferriol (1984: 256); en otro sentido, puede verse la concepción evolutiva y cambiante del consentimiento matrimonial mantenida por De Pablo Contreras (2011: 513 y ss.).

22 En este sentido, la SAP de Málaga (7a), de 26 de diciembre de 2003. Se apunta, sin embargo, por algún autor, que la finalidad del matrimonio es la de fundar una familia y, por tanto, sobre esta habrá de recaer el consentimiento matrimonial (García Herrera, 2015: 14). También lo hace la DGRN en la Instrucción de 31 de enero de 2006 sobre matrimonios de complacencia, aunque de forma más completa, cuando afirma que «el consentimiento matrimonial es existente, auténtico y verdadero, cuando los contrayentes persiguen, con dicho enlace, fundar una familia. Aunque el Código Civil español no detalla cuál es la finalidad del matrimonio, sí contiene una "determinación legal" de los "derechos y deberes de los esposos", de modo que es claro que cuando los cónyuges contraen matrimonio deben querer asumir tales derechos y deberes. Por tanto, cuando los contrayentes se unen en matrimonio excluyendo asumir las finalidades, propiedades o efectos esenciales del matrimonio, el consentimiento matrimonial declarado es "simulado" y el matrimonio es nulo por falta de consentimiento matrimonial». 
matrimonio de una persona el de su capacidad natural para prestar de forma consciente el consentimiento matrimonial (art.45 Cc)». Y ello sin olvidar que el matrimonio, como todo negocio jurídico, «exige una real y válida voluntad no aquejada de vicios invalidantes, de suerte que la voluntad matrimonial será inexistente si faltan los presupuestos psicológicos de la decisión interna del contrayente y, entre ellos, un suficiente ejercicio de su razón»; la existencia de anomalías psíquicas no constituye por sí misma impedimento para que la persona afectada por las mismas pueda contraer matrimonio ${ }^{23}$.

En este mismo sentido, la Sala Primera del Tribunal Supremo considera que la

presunción general de capacidad admite excepciones por las que debe comprobarse previamente la capacidad natural de la persona para prestar consentimiento a un acto determinado, y así sucede con el matrimonio porque el artículo 56 del Cc dispone en el párrafo segundo que «si alguno de los contrayentes estuviere afectado por deficiencias o anomalías psíquicas, se exigirá dictamen médico sobre su aptitud para prestar consentimiento». Paso previo a exigir referido dictamen es constatar por el Encargado del Registro en la entrevista reservada o por la documental obrante en el expediente, la existencia de alguna deficiencia o anomalía psíquica. Y se exige tal dictamen en vez de negar sin más capacidad, porque en el matrimonio se requiere, como en cualquier otro negocio jurídico, una real y válida voluntad no aquejada de vicios invalidantes, pero, sin embargo, la solución acogida por nuestro Derecho vigente, en línea con los antecedentes históricos, es excluir que las deficiencias o anomalías psíquicas constituyen por sí mismas impedimento para que la persona afectada por las mismas pueda contraer matrimonio. Tal solución se compadece con catalogar el derecho del matrimonio entre los derechos humanos y su protección constitucional (SSTS 8 de noviembre de 2017 y 15 de marzo de 2018).

Así pues, el instructor puede, a lo largo de la tramitación del expediente matrimonial, exigir el dictamen médico que disipe las dudas acerca de la capacidad para prestar el consentimiento de uno de los contrayentes ${ }^{24}$; en este sentido, parece que el momento más oportuno será el trámite de audiencia personal, reservada y por separado de cada contrayente previsto en el art. 246 $\mathrm{RRC}$, que persigue verificar «la inexistencia del vínculo de ligamen o cualquier

23 RDGRN de 18 de septiembre de 2008.

24 Según el art. 245.2 RRC, si el instructor estima que alguno de los contrayentes está afectado por deficiencias o anomalías psíquicas, recabará del médico del Registro Civil o de su sustituto el dictamen facultativo oportuno. Se ha apuntado a este respecto la conveniencia de que el dictamen lo emitiera un médico especialista, véase Puig Ferriol, ult. loc.cit. 
otro obstáculo legal para la celebración $»^{25}$; pero si después de esta se tuviera noticia de la discapacidad mental o intelectual de uno de los contrayentes nada impide que el instructor solicite en ese momento el dictamen médico con independencia de lo avanzado del procedimiento ${ }^{26}$. También si se recurre la denegación de la autorización del matrimonio y se estima el recurso, la DGRN puede ordenar la retroacción de las actuaciones a fin de que el interesado sea examinado por el médico forense ${ }^{27}$.

Incluso en los matrimonios celebrados sin tramitación del expediente correspondiente, el juez o funcionario encargado del Registro, antes de practicar la inscripción, «deberá comprobar si concurren los requisitos legales para su celebración» (art. 65 CC) y, por lo tanto, si en "las declaraciones complementarias oportunas» (art. 256 in fine RRC) se apreciara la existencia de discapacidad mental o intelectual, deberá solicitarse el dictamen médico correspondiente $e^{28}$.

Recabado el informe, este constituye la clave para la autorización del matrimonio, de suerte que, en la totalidad de los casos estudiados, se deniega esta cuando aquel es desfavorable ${ }^{29} \mathrm{y}$, en alguna ocasión, incluso, aun siendo favorable, queda vedada la celebración del matrimonio ${ }^{30}$. El carácter no vinculante del dictamen médico es defendido en la doctrina por Díaz Martínez (2013), quien, siguiendo el criterio de la RDGRN de 1 de diciembre de $1987^{31}$, considera que la discrepancia del encargado con el dictamen emitido

25 La RDGRN de 20 de enero de 1995 califica de «trámite esencial» la audiencia reservada y por separado, necesaria para conocer las verdaderas intenciones de los contrayentes; el instructor debe extremar las garantías formales y materiales que el expediente le proporciona a tal fin.

26 Así sucede en las RRDGRN de 17 de diciembre de 1993 y de 20 de enero de 1995.

27 RRDGRN de 19 de octubre de 2011 (11a) y de 18 de julio de 2013 (47a)

28 RRDGRN de 11 de diciembre de 1996 y de 31 de marzo de 2014 (98a).

29 Con base en un dictamen médico desfavorable no se autoriza el matrimonio en las RRDGRN de 27 de julio y de 17 de diciembre de 1993, 20 de enero de 1995, 23 de octubre de 1996, 18 de octubre de 1999, 29 de enero y 23 de octubre de 2004.

RDGRN de 2 de junio de 1999.

31 En esta resolución, la DGRN, tras afirmar el carácter no vinculante del dictamen y aceptar, ab initio, el criterio del instructor que no autoriza el matrimonio a pesar del dictamen médico favorable al que se suma el Ministerio Fiscal, estima el recurso, revoca el auto apelado y ordena al juez encargado que autorice el matrimonio: "Ahora bien, aunque indudablemente el dictamen facultativo no es vinculante para el Encargado, si aquél ha entendido, como conclusión de un estudio razonado que "en la entrevista exploratoria ambos mostraron un conocimiento aceptable sobre lo que suponía el matrimonio y sus consecuencias, y se podía apreciar un grado aceptable de 
para ser legítima debe fundarse «en su convicción sobre la falta de capacidad de los contrayentes, deducida de su apreciación y examen directo y personal de éstos", de manera que, si entiende que los futuros contrayentes tienen un conocimiento suficiente sobre el matrimonio y sus consecuencias y aprecia un grado aceptable de voluntad, puede autorizar el matrimonio, pese a que el dictamen médico fuere desfavorable y a la inversa ${ }^{32}$.

A mi juicio, no resulta fácil sostener el carácter no vinculante del dictamen, en primer lugar, por el peso que el propio legislador le reconoce al constituir, junto con la audiencia personal, la única prueba debida, cuando, en otras situaciones, ordena, por ejemplo, la audiencia de los parientes más próximos (art. $759 \mathrm{Lec}$ ); en segundo lugar, porque de lo que se trata aquí es de dilucidar si hay aptitud para prestar el consentimiento, por tanto, si la hay — según el informe- deberá autorizarse el matrimonio, que se configura como un derecho fundamental de las personas y, como tal, su privación debe ser interpretada restrictivamente, y si no la hay — según el dictamen—, se autoriza un acto que podrá ser atacado de nulidad sobre la base de ese mismo informe médico que el encargado del Registro no atendió; y, en tercer lugar, su paralelismo con lo dispuesto para el testamento del incapacitado que solo podrá autorizarse si dos facultativos responden de su capacidad (art. $665 \mathrm{CC})^{33}$.

Conviene referirse, a continuación, a la aplicación práctica del control de la existencia del consentimiento matrimonial que se lleva a cabo en dos momentos, antes y después de la celebración del matrimonio; para ello, además de la casuística que recogen las resoluciones de la Dirección General de los Registros y del Notariado, como consecuencia del recurso del auto que autoriza o no la celebración del matrimonio, debe hacerse referencia, asimismo, a la que se origina en sede judicial cuando se ejercita la acción de nulidad ex art. 73 con motivo de la falta de consentimiento del contrayente aquejado de una anomalía o deficiencia psíquica.

voluntad como para prestar el consentimiento válido”, es obvio que la discrepancia del Encargado, para ser legítima, ha de estar fundada en su convicción sobre la falta de capacidad de los contrayentes, deducida de su apreciación y examen directo y personal de éstos. No ha sido éste el fundamento del auto desfavorable... La posibilidad, en fin, de que ciertas deficiencias o anomalías psíquicas, no graves, no impidan el matrimonio se desprende claramente del propio artículo 56 que es la norma específica aplicable al caso; se halla en consonancia con la presunción general de capacidad... y con la esencia del mismo ius nubendi, derecho fundamental de la persona reconocido por la Constitución (art. 32), que no puede ser desconocido ni menoscabado más que en casos evidentes de falta de capacidad».

32 Véase Díaz Martínez (2013: 717); también Campuzano Tomé (2010: 165).

33 En este sentido, Puig Ferriol (1984: 256); Marín López (2009: 177). 


\subsection{El control inicial de la capacidad para consentir válidamente: la doctrina de la DGRN}

Del conjunto de resoluciones de la DGRN que han recaído como consecuencia del recurso interpuesto contra el auto dictado por el encargado del Registro Civil autorizando o denegando la celebración del matrimonio pueden inferirse las siguientes afirmaciones:

1. ${ }^{\text {a }}$ La finalidad del dictamen médico es verificar la concurrencia de un requisito esencial del matrimonio, el consentimiento matrimonial (art. 45 CC), cuya falta provoca la nulidad del enlace (art. 73.1 ${ }^{\circ} \mathrm{CC}$ ). Se considera, pues, un valioso instrumento exigible en la instrucción del expediente matrimonial (art. 56.2 CC) y recomendable, incluso, en aquellos matrimonios que se celebran sin expediente previo, como por ejemplo, el matrimonio en peligro de muerte. A este respecto, el Centro Directivo apunta que

la misión de las personas facultadas para autorizar el matrimonio del que se halle en peligro de muerte es especialmente delicada porque las circunstancias subjetivas del contrayente pueden hacer dudar si está en condiciones psíquicas suficientes para prestar el consentimiento matrimonial, el cual es un requisito imprescindible para la validez del matrimonio. Por esto, los autorizantes de tales enlaces han de extremar el cuidado en la apreciación de la capacidad del afectado. Sin duda, los Jueces Encargados del Registro civil, cuando la urgencia del caso lo permita, deberán recabar el oportuno dictamen médico, pues aunque éste está previsto para el expediente previo al matrimonio y en este expediente debe emitir aquél el Médico forense, concurren las mismas o más fuertes razones para que, si ello es posible, no haya de prescindirse de esta garantía en el matrimonio en peligro de muerte (RDGRN 17 de febrero de 2010) ${ }^{34}$.

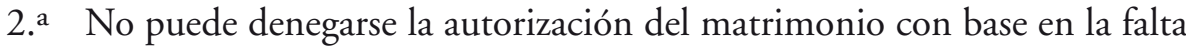
de capacidad para consentir sin el dictamen médico preceptivo, de suerte que si este falta, recurrido el auto, la DGRN ordena la retroacción del expediente y la práctica de esta prueba (RRDGRN 19 de octubre de 2011 y 18 de julio de 2013).

34 Doctrina acogida en el nuevo art. 52 CC modificado por la disposición final primera de la Ley de Jurisdicción Voluntaria de 2 de julio de 2015 que exige, además de los dos testigos mayores de edad, y siempre que sea posible, el dictamen médico. 
3. ${ }^{a} \quad$ A pesar de sostener el carácter no vinculante del dictamen médico, el Centro Directivo no se aparta de lo dispuesto más que en una ocasión, en la que, a nuestro juicio, se vulnera claramente el ius nubendi de la persona con discapacidad promotora del expediente matrimonial (RDGRN de 2 de junio de 1999); el dictamen favorable y la existencia de vida familiar debieran haber sido considerados elementos suficientes para autorizar el matrimonio, derecho fundamental cuyo ejercicio no puede quedar sometido a la opinión de terceros sobre el matrimonio proyectado y que solo requiere el consentimiento pleno y libre de los esposos que, a tenor del dictamen médico, aquí sí existía ${ }^{35}$.

4. ${ }^{a}$ Se aprecia un control de la influencia indebida y de la simulación que impiden la celebración del matrimonio. Las personas con discapacidad mental e intelectual son fácilmente influenciables y el expediente previo, a través de la entrevista reservada, personal y por separado de los contrayentes, es el momento adecuado para detectar si la voluntad de contraer matrimonio es libre y no ha sido la persona con discapacidad manipulada por el otro contrayente que perseguiría, fraudulentamente, las ventajas anudadas a la institución matrimonial. En este sentido, el elemento de extranjería más la fragilidad de la persona con discapacidad son antecedentes determinantes que exigen un particular celo en el instructor del expediente (RRDGRN 17 de diciembre de 1993, de 20 de enero de 1995, de 16 de junio de 2011, 19 de octubre de 2011 y 2 de septiembre de 2013) y que, sin embargo, no alertaron al encargado del Registro Civil del Consulado General de España en el caso enjuiciado en la STS de 15 de marzo de $2018^{36}$.

35 De una parte, el dictamen médico refiere un retraso mental ligero y, «desde el punto de vista psicométrico una limitación afectiva muy ligera que le permite tener aptitud para prestar consentimiento matrimonial», y, de otra, de la entrevista personal con los contrayentes se desprende que los promotores viven juntos, que son padres de un niño y que la promotora no sabe ni leer ni escribir. Intervienen asimismo la madre de la promotora, que no se opone al matrimonio, y los tíos, que sí lo hacen sobre la base de la discapacidad de la sobrina que «tiene perturbadas las facultades mentales, sin llegar a ser subnormal, pero necesita una persona que la oriente» y que ha sido declarada incapacitada para regir su persona y bienes y sometida a tutela.

36 Esta sentencia versa sobre la nulidad de un matrimonio celebrado en la República Popular China por un ciudadano español que, al momento de contraer matrimonio, estaba incurso en un proceso de modificación de la capacidad que concluyó con la restricción de la capacidad de obrar para todos los actos de gobierno sobre su persona y bienes y el sometimiento a tutela, que fue deferida a su hija mayor; se desestima el recurso de apelación planteado por la persona con discapacidad en el que solicitaba 
5. ${ }^{a}$ Respecto del consentimiento matrimonial, en líneas generales, se observan, de una parte, referencias expresas al consentimiento en general («falta de capacidad del recurrente para prestar un consentimiento plenamente consciente ${ }^{37}$, el consentimiento que pueda prestar el explorado se encuentra alterado, por lo tanto, no apto para prestarlo ${ }^{38}$ o el deterioro cognitivo leve le imposibilita en estos momentos poder prestar consentimiento válido para contraer matrimonio $\left.{ }^{39}{ }\right)$ y al consentimiento matrimonial en particular («que no llega a comprender la trascendencia del hecho matrimonial ${ }^{40}$, no posee la suma de conocimientos acerca de los derechos y deberes sociales, juicio suficiente para aplicarlos en un caso concreto como el que nos ocupa o firmeza de voluntad precisa para obrar con conocimiento ${ }^{41}$, no es capaz para prestar el consiguiente consentimiento matrimonial con conocimiento de causa ${ }^{42}$, no es capaz de autogobernarse y tomar decisiones legales como el matrimonio ${ }^{43} \mathrm{o}$ conocimiento aceptable sobre lo que supone el matrimonio y sus consecuencias y se podía apreciar un grado aceptable de voluntad como para prestar consentimiento válido $\left.{ }^{44}{ }\right)$; y, de otra, se observa el establecimiento de un paralelismo a partir de la edad fijada en el dictamen médico, de manera que, si esta es inferior a los 14 años, se deniega la autorización del matrimonio (RRDGRN de 17 de diciembre de 1993, de 20 de enero de 1995 y de 2 de junio de 1999), y si es superior, se autoriza la celebración (RDGRN de 12 de marzo de 1994). Este paralelismo resulta, a mi juicio, inadecuado desde el momento en que la dispensa de edad a partir de los 14 años está más relacionada con la capacidad de procreación que con la capacidad natural o de discernimiento y las correspondencias o equivalencias de edad se refieren a niveles de inteligencia y no a las experiencias y

que su cónyuge fuera nombrada tutora. El cónsul español, en la entrevista personal con el contrayente, no apreció motivos para solicitar el dictamen médico, aunque ha de reconocerse que son hechos probados que la información sobre la discapacidad del contrayente (enfermedad de Alzheimer) y la pendencia de un proceso de modificación de la capacidad se ocultaron al funcionario chino que ofició el matrimonio y al encargado de inscribirlo en el Registro Civil del Consulado General de España. RDGRN 27 de julio de 1993.

38 RDGRN de 18 de octubre de 1999.

39 RDGRN de 16 de junio de 2011.

40 RDGRN de 2 de septiembre de 2013.

41 RDGRN de 21 de febrero de 2014.

42 RDGRN de 24 de marzo de 1994.

43 RDGRN de 23 de octubre de 1996.

44 RDGRN de 1 de diciembre de 1987. 
las vivencias de la persona. Luego debe huirse de la equiparación menor edad y mayor edad con discapacidad intelectual.

\subsection{El control ex post de la capacidad para consentir: la nulidad matrimonial}

No son muchas las ocasiones en las que los tribunales se han tenido que pronunciar sobre la nulidad del matrimonio por incapacidad para consentir en uno de los contrayentes ${ }^{45}$, pero cuando lo han hecho se han atenido, en primer lugar, al carácter excepcional de la declaración de nulidad matrimonial y la rigurosa prueba que, conforme al art. $217 \mathrm{Lec}$, corresponde a quien invoca la nulidad, que deberá acreditar la falta de consentimiento, la afectación de las facultades del intelecto y/o la voluntad y su directa correlación causal ${ }^{46}$;

45 El Tribunal Supremo lo ha hecho en la Sentencia de 14 de julio de 2004, que no estima el recurso de casación contra la sentencia que consideraba plenamente probada la falta de capacidad para consentir el matrimonio y que, en consecuencia, declara la nulidad matrimonial; en la Sentencia de 29 de abril de 2015, que tampoco estima el recurso de casación contra la sentencia de la Audiencia que confirma la del juzgado declarando no haber lugar a la nulidad matrimonial al no probarse la falta de capacidad en el contrayente y deduciéndose la validez del consentimiento de otros elementos; y en la Sentencia de 15 de marzo de 2018, en la que se estima el recurso de casación y se concluye la existencia de aptitud para contraer matrimonio, negada en la sentencias de instancia y deducida por el TS de otros elementos probados en el curso del procedimiento.

46 Así, en las SSAP Madrid (22a), de 10 de enero de 2003 y 15 de marzo de 2013, se afirma que "por el carácter excepcional de tal institución jurídica, al negarse validez a posteriori a un contrato matrimonial aparente, los Tribunales han de actuar con especial prudencia respecto de los elementos fácticos y resultado probatorio ofrecido a su ponderación, de tal modo que sólo cuando conste de modo inequívoco la concurrencia de circunstancias susceptibles de ser encuadradas en alguna de las previsiones del artículo 73, puede llegarse a proclamar la solución sanadora que se propugna, ya que la misma entra en colisión con el principio del favor matrimonii, que ha de ser proyectado con bastante más rigor, como se ha apuntado, que en las figuras de la separación y el divorcio, que no niegan la existencia del matrimonio, sino que parten necesariamente del mismo para sancionar, con uno u otro alcance, la crisis surgida en las relaciones posteriores de los esposos». O la SAP de Burgos ( $\left.3^{\text {a }}\right)$ de 28 de enero de 2002 que señala que «la falta de dicho dictamen médico no invalida el matrimonio, siendo necesario para poder declarar su nulidad la prueba de que en el momento de la celebración, el contrayente no podía prestar válidamente el consentimiento matrimonial como consecuencias de sus deficiencias o anomalías psíquicas». Y en último lugar, la SAP de Islas Baleares (4a) de 18 de junio de 2014 en la que el tribunal recuerda "que la capacidad del otorgante se debe presumir en autos salvo prueba solvente en 
pudiéndose deducir la existencia del consentimiento de otros elementos como la duración de la convivencia y la existencia de hijos comunes ${ }^{47}$, la actividad patrimonial de los cónyuges ${ }^{48}$, la realización de actos jurídicamente trascendentes sin que aquellas deficiencias fueran apreciadas por los operadores jurídicos (notarios, encargados de Registro Civil...) ${ }^{49}$; o el hecho de que previamente el juez que dicta el divorcio a instancias de la persona con discapacidad descarte expresamente que la tramitación de un procedimiento de modificación de la capacidad fuera obstáculo para ello, apreciando, por tanto, capacidad suficiente, y el tiempo que transcurre desde la conocida celebración del matrimonio y su impugnación, que, por otra parte, no ejercitan ni el Ministerio Fiscal ni el tutor, de donde se infiere que no existía abuso o manipulación, ni invalidez del matrimonio, pues de lo contrario el tutor, en el correcto ejercicio de las funciones tutelares, y el Ministerio Fiscal, en cumplimiento de su función de fiscalización y supervisión hubieren puesto fin a esta situación, ejercitando tempestivamente la acción de nulidad ${ }^{50}$.

Se atiende, pues, muy acertadamente, a otros elementos fácticos y circunstancias concurrentes para defender la validez del matrimonio en detrimento de un dictamen médico anterior y abstracto que, por sí solo, no puede abocar a la nulidad del matrimonio contraído por la persona con discapacidad ${ }^{51}$.

contrario de quien invoca la incapacidad, es decir, de la parte actora. De suerte que la falta de prueba al respecto, o las eventuales dudas en cuanto a la misma, obligan al Juez, primero, y a la Sala después, a desestimar una pretensión no suficientemente clara (art. 217 Lec)».

SAP Barcelona (12a), de 21 de febrero de 2001: «falta todo elemento de prueba para apreciar la nulidad invocada y por el contrario existen una serie de actos reveladores de la libertad de la prestación del consentimiento válido, cuales la inexistencia de impedimento en el expediente matrimonial (ya que el ius connubi del artículo $56 \mathrm{ni}$ siquiera precisó dictamen médico de aptitud), y por otro lado el embarazo del primer hijo antes de contraer el vínculo, y el nacimiento del segundo revelan una continuidad en las relaciones matrimoniales y afectivas (incompatibles con la alegada incapacidad)». Así la SAP de Barcelona (12a) de 10 de marzo de 2016 sostiene que, además de la duración del matrimonio (7 años), «los actos coetáneos y posteriores al matrimonio con la actividad patrimonial de los cónyuges evidencian una comunidad de intereses dentro de la sociedad de gananciales, la adopción de decisiones y su plasmación en documentos notariales» que permiten presumir que el consentimiento no estuvo viciado.

49 Véase la SAP Sevilla (2a) de 18 de diciembre de 2013.

50 STS de 15 de marzo de 2018.

51 En sentido contrario, el voto particular formulado por el magistrado Arroyo Fiestas en la STS de 15 de marzo de 2018 defiende que, a la vista de lo concluyente de los 
$\mathrm{Y}$ en segundo lugar, se parte de que la capacidad para contraer matrimonio no es la plena capacidad de obrar, no se requiere que los contrayentes estén en pleno goce de sus facultades mentales e intelectuales, basta la capacidad natural, el discernimiento suficiente para conocer el compromiso que adquieren ${ }^{52}$.

En este sentido, la Sentencia del Tribunal Supremo de 15 de marzo de 2018 en la que, cuestionada la validez del matrimonio celebrado por una persona con discapacidad mental, el Alto Tribunal estima el recurso de casación al entender que

no ha quedado suficientemente desvirtuada la presunción de capacidad para la prestación de consentimiento matrimonial y que la consideración del matrimonio como derecho humano derivado de la dignidad de la persona y manifestación del libre desarrollo de la personalidad, también cuando se alcanza una edad avanzada, deben inclinar a reforzar el principio del favor matrimonii... Ni el estar incapacitado ni el padecer discapacidad intelectual son hechos que excluyan por sí mismos la aptitud para celebrar el matrimonio, (por ello) la sentencia recurrida restringe injustificadamente el derecho a contraer matrimonio, derecho reconocido a las personas con discapacidad por los tratados internacionales sobre derechos humanos y por la Convención sobre los Derechos de las personas con discapacidad.

En conclusión, puede afirmarse que el art. 56.2 CC y su aplicación por los operadores jurídicos no ha despertado especiales críticas, al contrario: se le considera respetuoso con el ius nubendi de las personas con discapacidad psíquica o intelectual, al favorecer su celebración — que constituye la regla

dictámenes médicos, debe deducirse la incapacidad de la persona con discapacidad para contraer matrimonio. A mi juicio, es preferible y más acorde con la naturaleza del ius connubii dar prevalencia a la apreciación in concreto de la capacidad para contraer matrimonio que efectúa el funcionario encargado de inscribir el matrimonio y la que realizó, en su momento, el juez que declaró el divorcio, que expresamente afirmó que no constituía un impedimento la tramitación paralela de un proceso de modificación de la capacidad de obrar. Esta apreciación in concreto de la capacidad sumada a la inactividad del tutor y del Ministerio Fiscal permiten sostener la validez de un acto que no se cuestionó en vida del otorgante, quien, a pesar de su vulnerabilidad, pudo comprender la naturaleza del matrimonio y querer sus efectos y, por tanto, consentir válidamente. El dictamen médico in abstracto no sirve para destruir la presunción de capacidad para consentir el matrimonio, si existe la apreciación in concreto de capacidad y si esta puede deducirse de otros elementos probados.

52 SAP Madrid (22a), de 10 de enero de 2003 y 15 de marzo de 2013. 
general - si concurre la capacidad natural de entender qué es el matrimonio y querer los efectos que le son propios ${ }^{53}$.

\section{LA LEY $15 / 2015$, DE 2 DE JULIO, DE JURISDICCIÓN VOLUNTARIA}

La Ley 15/2015, de 2 de julio, de Jurisdicción Voluntaria, modifica, en su disposición final primera, varios aspectos sustanciales relacionados con la capacidad para contraer matrimonio y el consentimiento matrimonial. En primer lugar, se suprime la posibilidad de obtener dispensa del impedimento de edad al menor mayor de 14 años, de suerte que hoy la emancipación es requisito para contraer matrimonio y no efecto de su celebración ${ }^{54}$. La elevación de la edad mínima aleja la capacidad para contraer matrimonio de la antigua capacidad para procrear y nos sitúa una vez más en el terreno de la capacidad natural de entender y querer; se pretende con ello, además, contribuir a la erradicación de los matrimonios forzados y precoces en sintonía con el resto de los países de nuestro entorno ${ }^{55}$.

En segundo lugar, se da nueva redacción al segundo párr. del art. 52 del Código Civil, destinado a la celebración del matrimonio en peligro de muerte que, al igual que en la regulación anterior, no requerirá la previa tramitación del acta o expediente matrimonial, pero sí la presencia, en su celebración, de dos testigos mayores de edad; y se añade, como novedad, la exigencia, "cuando el peligro de muerte derive de enfermedad o estado físico de alguno de los contrayentes, [de] dictamen médico sobre su capacidad para la prestación del consentimiento y la gravedad de la situación, salvo imposibilidad acreditada, sin perjuicio de lo establecido en el artículo 65».

Y, en tercer lugar, modifica el apdo. segundo del art. 56, al que da nueva una redacción del siguiente tenor: "Si alguno de los contrayentes estuviere afectado por deficiencias mentales, intelectuales o sensoriales, se exigirá por el Secretario Judicial, Notario, Encargado del Registro civil o funcionario que tramite el acta o expediente, dictamen médico sobre su aptitud para prestar el

53 Posición aislada en la doctrina es la mantenida por De Pablo Contreras (2011: 521) para quien, tras la reforma del Código Civil por Ley 15/2005, debe distinguirse la regla de la "capacidad natural» que se aplica al matrimonio de un hombre y una mujer y la «capacidad plena o capacidad para contratar» que se exige a los matrimonios entre personas del mismo sexo; regla que extiende a las personas con discapacidad. Se modifica para ello el art. 48 del Código Civil.

55 Medida prevista en el II Plan Estratégico Nacional de la Infancia y la Adolescencia (2013-2016), aprobado por Acuerdo del Consejo de Ministros el 5 de abril de 2013, pg. 66. Véase ampliamente sobre esta cuestión Aguilera Rull (2017: 371-397). 
consentimiento». Esta nueva redacción introduce dos novedades respecto del texto procedente de la reforma de 1981:

a) Se especifican los sujetos que han de solicitar el dictamen; sin duda, para expresar su obligatoriedad sea cual sea el cauce elegido por los contrayentes para la celebración del matrimonio ${ }^{56}$.

b) Para adaptar la terminología del Código Civil que habla de deficiencias y anomalías psíquicas, más propia de modelo médico-rehabilitador, el legislador adopta la definición del art. $1 \mathrm{CNY}$ que incluye en las personas con discapacidad a "aquellas que tengan deficiencias físicas, mentales, intelectuales o sensoriales»; se prescinde, naturalmente, de las deficiencias físicas que en nada afectan a la prestación del consentimiento $y$, sin embargo, y sin duda por inadvertencia, se mantienen las deficiencias sensoriales que, al igual que las físicas, no tienen repercusión en la aptitud para consentir, toda vez que son aquellas que afectan a los sentidos y abarcan la discapacidad visual y la auditiva, pero también otras como la discapacidad gustativa, olfativa o la discapacidad somatosensorial (falta de sensibilidad al tacto, calor, frío y dolor... $)^{57}$.

Esta nueva redacción, cuya entrada en vigor estaba prevista para el 30 de junio de 2017, provocó una esperable reacción del movimiento asociativo de la discapacidad que obligó a adoptar una Resolución-circular de 23 de diciembre de 2016 con el fin de «clarificar los criterios de interpretación y aplicación respecto de la documentación exigida a los contrayentes que estuvieren afectados por deficiencias mentales, intelectuales o sensoriales». En esta, se realiza una interpretación correctora, en aplicación de los arts. 12 y 23 CNY y en tanto se tramita la modificación legal correspondiente:

Debe interpretarse siempre de manera estricta y en relación a supuestos excepcionales en los que la discapacidad afecte de forma evidente e impeditiva, aun

56 En correspondencia con la nueva redacción del art. 51, que atribuye la competencia para constatar mediante acta o expediente el cumplimiento de los requisitos de capacidad de ambos contrayentes y la inexistencia de impedimentos o su dispensa, o cualquier género de obstáculos para contraer matrimonio al secretario judicial, notario o encargado del Registro Civil del lugar del domicilio de uno de los contrayentes o al funcionario diplomático o consular encargado del Registro Civil si residiesen en el extranjero.

57 No es esta la justificación que se aireaba en los momentos críticos de denuncia por parte del movimiento asociativo que atribuía este grave error a la copia indiscriminada de textos preconstitucionales. 
proporcionados los apoyos precisos, a la capacidad para prestar el consentimiento, y lógicamente no a aquellos supuestos en que la discapacidad afecte tan sólo a los medios, canales o soportes de emisión de ese consentimiento o nada tenga que ver ni guarde relación con la aptitud para prestarlo.

En consecuencia, procede establecer como criterio de aplicación que la exigencia por parte del Letrado de la Administración de Justicia, Notario, Encargado del Registro civil o funcionario que tramite el acta o expediente matrimonial, de dictamen médico sobre la aptitud para prestar consentimiento de aquellos contrayentes que estuvieren afectados por deficiencias mentales, intelectuales o sensoriales, se deberá entender limitada exclusivamente a aquellos casos en los que la deficiencia afecte de forma sustancial a la prestación del consentimiento por el interesado en cuestión.

En caso de contrayentes que presenten estas deficiencias y siempre con el propósito de favorecer la celebración del matrimonio, el letrado de la Administración de Justicia, Notario, Encargado del Registro civil o funcionario que tramite el acta o expediente matrimonial podrá recabar el auxilio y la colaboración de las Administraciones o entidades de iniciativa social de promoción y protección de los derechos de las personas con discapacidad en la provisión de los apoyos humanos, técnicos y materiales precisos que faciliten la emisión, la interpretación y la recepción del consentimiento.

En todo caso, la resolución adoptada por la autoridad competente será susceptible de ser recurrida de conformidad con el régimen de recursos previsto en la legislación registral.

Esta resolución-circular tiene gran importancia desde el momento en que consigna una interpretación correctora y extensiva de la norma que va a ser adoptada en su integridad en la reforma posterior del texto legal y que responde a las reivindicaciones del movimiento asociativo que, como veremos a continuación, no modifica en lo sustancial el art. 56 en su redacción inicial, aunque sí subraya el reconocimiento en abstracto de la capacidad para contraer matrimonio de todas las personas con discapacidad.

\section{LA LEY 4/2017, DE 28 DE JUNIO, DE MODIFICACIÓN DE LA LEY 15/2015, DE 2 DE JULIO, DE LA JURISDICCIÓN VOLUNTARIA}

Como se expone en su preámbulo, esta ley es la respuesta a la demanda de la sociedad civil que, a través del movimiento asociativo de la discapacidad, «ha planteado a las fuerzas políticas, al Legislador y al Gobierno de la Nación, la modificación de este precepto para establecer, eliminando restricciones y proporcionando apoyos, un régimen legal favorecedor, de la celebración del 
matrimonio, si esa es la voluntad de las personas con discapacidad». Se persigue, además, aclarar que la intención de la reforma es «favorecer la celebración del matrimonio de las personas con discapacidad, evitando cualquier sombra de duda sobre su capacidad para contraer matrimonio». Pues bien, esta ley, además de retrasar la entrada en vigor, una vez más, de la Ley de Registro Civil a 30 de junio de 2018, modifica la disposición final primera (apdo. 9) de la Ley 15/2015, de 2 de julio de Jurisdicción Voluntaria, que, a su vez, modifica el art. 56 del Código Civil y la disposición final cuarta que da nueva redacción a algunos apartados del art. 58 de la Ley de Registro Civil de 2011 para cohonestar lo dispuesto en uno (56.2 CC) y otro precepto (art. 58.5 LRC 2011).

La nueva redacción del párrafo segundo del art. 56 del Código Civil, que entrará en vigor el 30 de junio de 2018, reproduce el contenido de la resolución-circular de la DGRN de 23 de diciembre de 2016 y se reitera, como segundo párrafo, en el apdo. quinto del art. 58 LRC:

El Letrado de la Administración de Justicia, Notario, Encargado del Registro Civil o funcionario que tramite el acta o expediente, cuando sea necesario, podrá recabar de las Administraciones o entidades de iniciativa social de promoción y protección de los derechos de las personas con discapacidad, la provisión de apoyos humanos, técnicos y materiales que faciliten la emisión, interpretación y recepción del consentimiento del o los contrayentes. Solo en el caso excepcional de que alguno de los contrayentes presentare una condición de salud que, de modo evidente, categórico y sustancial, pueda impedirle prestar el consentimiento matrimonial pese a las medidas de apoyo, se recabará dictamen médico sobre su aptitud para prestar el consentimiento.

Las novedades introducidas son dos: de una parte, la posibilidad de recabar la provisión de apoyos humanos técnicos y materiales que faciliten la emisión, interpretación y recepción del consentimiento y, de otra, sustituir las referencias a la discapacidad mental, intelectual o sensorial por la expresión «cuestiones de salud». Esta nueva redacción no merece, a mi entender, un juicio favorable; hubiere sido preferible eliminar la referencia a la discapacidad sensorial y mantener la discapacidad mental e intelectual como factor que "puede» incidir en la validez del consentimiento, que es lo único que, inicialmente, contemplaba el precepto: la aptitud para prestar el consentimiento matrimonial. Hablar de salud es equívoco e inexacto, el mismo legislador hace referencia a la enfermedad o estado físico de los contrayentes, por ejemplo, en el matrimonio celebrado en peligro de muerte (art. 52 CC) y no habla de salud, que parece un término demasiado amplio para acotar situaciones excepcionales. 
Se puede decir críticamente que el legislador de 2015 es un legislador insistente que reitera el contenido de los preceptos, aunque, a veces, lo hace de forma incompleta. En este sentido, los arts. del Código que regulan el matrimonio civil y que nos interesan son, de una parte, el apdo. primero del art. 51, que establece la competencia para la instrucción del acta o expediente matrimonial cuya finalidad es «constatar el cumplimiento de los requisitos de capacidad de ambos contrayentes y la inexistencia de impedimentos o su dispensa o cualquier género de obstáculos para contraer matrimonio». Constatada la capacidad (edad) y la inexistencia de impedimentos (ligamen, muerte dolosa y parentesco) o su dispensa (muerte dolosa y parentesco colateral de tercer grado), queda por verificar la existencia de «cualquier género de obstáculo a la celebración». Y es aquí donde, a mi juicio, tiene cabida el control del consentimiento, su existencia y su veracidad. Pues bien, el nuevo art. 56 CC, objeto de toda esta controversia, establece, igualmente, la obligación de los contrayentes de acreditar "previamente en acta o expediente tramitado conforme a la legislación del Registro civil, que reúnen los requisitos de capacidad y la inexistencia de impedimentos o su dispensa, de acuerdo con lo previsto en este Código»; pero desaparece la referencia al control de cualquier otro obstáculo a la celebración (cuestiones relacionadas con el consentimiento) y se regula, a continuación, la exigencia del dictamen médico sin conexión con el párrafo anterior.

El contenido de estos dos preceptos se reitera en el art. 58 de la Ley de Registro Civil que, de forma más completa, coherente y sistemática, regula esta cuestión. El apartado segundo se refiere al expediente o acta: determina su finalidad, su carácter obligatorio, quién lo debe solicitar y quién lo debe tramitar. El apartado quinto alude a la audiencia personal, separada y reservada de los contrayentes para cerciorarse de su capacidad y de la inexistencia de cualquier impedimento. A continuación, se establece la posibilidad de solicitar informes y practicar pruebas - sean o no propuestas por los contrayentes- "para acreditar el estado, la capacidad o domicilio de los contrayentes o cualesquiera otros extremos necesarios para apreciar la validez de su consentimiento y la veracidad de su matrimonio». Y naturalmente, aquí se hace referencia al dictamen médico que permite determinar, en los casos de discapacidad mental o intelectual detectada por el instructor, si existe consentimiento y así conjurar la invalidez del matrimonio. Y es aquí solo donde, a mi juicio, debiera haberse incluido la posibilidad del instructor de solicitar «la provisión de apoyos humanos, técnicos y materiales que faciliten la emisión, interpretación y recepción del consentimiento del o de los contrayentes", posibilidad que no quedaba excluida en la regulación anterior toda vez que podían exigirse toda clase de informes y práctica de pruebas para dar cumplida finalidad al expediente. Ahora bien, debe reconocerse que estas referencias expresas a 
los apoyos que puedan precisar las personas con discapacidad son positivas y normalizan el ejercicio de sus derechos en igualdad con las demás personas ${ }^{58}$.

Pues bien, de la lectura conjunta de los tres preceptos en su versión definitiva, parece que el art. 56 debería haber reproducido de forma completa la finalidad del acta o expediente (comprobación de los requisitos de capacidad, inexistencia de impedimentos o cualquier género de obstáculo para la celebración del matrimonio). Y, a continuación, hacer referencia a las pruebas que preceptivamente deben practicarse en el caso de las personas con discapacidad mental o intelectual; esta reforma constituía una oportunidad para superar la exigencia del dictamen médico como única forma de determinar la aptitud para contraer matrimonio; podría haberse incluido la necesidad de contar con la audiencia de los parientes más próximos y con un informe social que completara la convicción del instructor ${ }^{59}$.

En todo caso, parece que la redacción dada al art. 56, que quería remarcar el carácter excepcional de la limitación para contraer matrimonio de las personas con discapacidad, ha optado por una regulación que lo que subraya es el carácter excepcional del dictamen, que incluye referencias a personas que anteriormente quedaban plenamente excluidas del ámbito del precepto, y la nueva expresión "cuestiones de salud» es tan amplia que casa mal con la vocación restrictiva del precepto.

En todo caso, como señala la Sentencia de 8 de noviembre de 2017:

58 El legislador justifica esta previsión en respuesta a la exigencia prevista en el art. 12.3 CNY cuando establece «que los Estados partes adoptarán las medidas pertinentes para proporcionar acceso a las personas con discapacidad al apoyo que puedan necesitar en el ejercicio de su capacidad jurídica» y en el art. 23 CNY.

59 En el procedimiento abierto por la Asociación de profesores de derecho civil para la mejora de la Propuesta de Código Civil elaborado en su seno, propuse una enmienda de adición en este sentido, que fue admitida y que pasó a formar parte como segundo inciso del art. 212-6.1. Este texto ha sido citado por la Sentencia de 8 de noviembre de 2017: «En el mismo sentido, la Propuesta de Código civil elaborada por la Asociación de Profesores de Derecho civil en el año 2017, que recoge las opiniones de los expertos sobre la materia, en su 212-6.1, tras declarar que no hay matrimonio sin consentimiento matrimonial, añade que "si alguno de los contrayentes, tenga o no su capacidad modificada, está afectado por trastornos o deficiencias mentales, intelectuales o sensoriales que pueden afectar a su capacidad de entender y querer, el instructor del expediente matrimonial se asegurará de su aptitud para prestar el consentimiento mediante las pruebas que considere oportunas, tales como la entrevista personal, la audiencia del entorno más próximo, el informe social y el dictamen médico"». Este texto, por inadvertencia, mantiene la referencia a la discapacidad sensorial, que se ha suprimido en la propuesta definitiva. 
En la redacción del art. 56 CC dada por la Ley 4/2017, de 28 de junio (y que todavía no está en vigor) se profundiza en esta tendencia al prever que, al tramitar el expediente matrimonial, solo en el caso excepcional de que alguno de los contrayentes presentare una condición de salud que, de modo evidente, categórico y sustancial, pueda impedirle prestar el consentimiento matrimonial pese a las medidas de apoyo, se recabará dictamen médico sobre su aptitud para prestar el consentimiento. De esta forma, se refuerza el desarrollo de la Convención sobre los derechos de las personas con discapacidad, hecho en Nueva York el 13 de diciembre de 2006, cuyo art. 23 establece la obligación de los Estados parte de evitar la discriminación contra las personas con discapacidad en todas las cuestiones relacionadas con el matrimonio y la familia y, con este fin, reconocer «el derecho de todas las personas con discapacidad en edad de contraer matrimonio, a casarse y fundar una familia sobre la base del consentimiento libre y pleno de los futuros cónyuges».

\section{EL CARÁCTER DISCRIMINATORIO DE LA REGLA APLICABLE A LAS PERSONAS CON DISCAPACIDAD}

¿Constituye esta regla especial —el dictamen médico-, destinada a asegurar la validez del matrimonio, una injerencia desproporcionada o arbitraria desde el prisma del art. $12 \mathrm{CEDH}$ ? ¿Constituye una discriminación por razón de discapacidad definida en el art. 2 CNY? ${ }^{60}$. ¿Es la regla especial o el medio propuesto, el dictamen médico, lo que se considera improcedente? La última reforma del Código Civil permite intuir que alguna de estas consideraciones se opone a la regulación de un procedimiento ad hoc para el matrimonio de las personas con discapacidad, cuando se establece, a instancias del movimiento asociativo, el carácter excepcional del dictamen médico.

Para responder adecuadamente a la cuestión formulada es necesario tener presente la finalidad que persigue el control de la existencia y veracidad del consentimiento, que no es otra que la validez del acto cuya celebración se autoriza $^{61}$. En este sentido, es acertada la perspectiva de la DGRN y del TS cuando afirman que exigir la capacidad natural para contraer matrimonio es coherente con su configuración como derecho humano, y, por lo tanto, respetuoso con

60 Por discriminación por motivos de discapacidad «se entenderá cualquier distinción, exclusión o restricción por motivos de discapacidad que tenga el propósito o el efecto de obstaculizar o dejar sin efecto el reconocimiento, goce o ejercicio en igualdad de condiciones, de todos los derechos humanos y libertades fundamentales en los ámbitos político, económico, social, cultural, civil o de otro tipo. Incluye todas las formas de discriminación, entre ellas, la denegación de ajustes razonables».

61 En este sentido, Serrano Gómez (2011: 561). 
los textos internacionales de derechos humanos de referencia (art. $12 \mathrm{CEDH}$ y art. $23 \mathrm{CNY}$ ); ahora bien, su calificación como negocio jurídico exige una voluntad libremente formada y no aquejada de vicios invalidantes ${ }^{62}$, que debe acreditarse ante el instructor del expediente, quien deberá auxiliarse de cuantos informes y pruebas precise para asegurarse de su existencia; y en este trámite procedimental se articula un instrumento de verificación que auxilia al instructor en la fase de control del consentimiento, el dictamen médico, que no debe verse como un obstáculo al ius connubi sino al contrario, como un elemento que permite sostener la validez del matrimonio y prevenir la influencia indebida; por tanto, alineado con el art. $12 \mathrm{CNY}$ que impone a los Estados la obligación de garantizar a las personas con discapacidad el ejercicio de su capacidad jurídica en iguales condiciones con los demás (que concluyen válidamente actos y negocios jurídicos) y evitar la influencia indebida.

No solo es susceptible de control el consentimiento en el matrimonio de las personas con discapacidad mental o intelectual, también lo es en el matrimonio in articulo mortis o en el matrimonio de complacencia; en estos casos, existen circunstancias (la discapacidad mental o intelectual, la inminencia de la muerte o el elemento de extranjería) que pueden afectar a la validez del consentimiento y, por ello, para despejar las dudas y a fin de conjurar la nulidad, se imponen determinadas cautelas, en nuestro caso, el dictamen médico que el legislador ha extendido al matrimonio celebrado en peligro de muerte ${ }^{63}$. Además, tal cautela permite detectar la existencia de influencia indebida, consecuencia de la fragilidad o vulnerabilidad que, a veces, presentan las personas con discapacidad mental o intelectual, dependientes de su entorno y de las personas que les dispensan atención y cuidados. Esta cautela cumpliría con la obligación impuesta a los Estados partes de establecer las salvaguardias

62 Como gráficamente describe Frison Roche (1995: 577), «el consentimiento nace de la voluntad: hay un vínculo creador entre la voluntad y el consentimiento, el consentimiento es hijo de la voluntad y este lazo no puede romperse, a no ser que exista un vicio del consentimiento".

63 En los matrimonios de conveniencia ha sido la Dirección General de los Registros y del Notariado la que ha perfilado los instrumentos de control del consentimiento, suministrando las pautas y estableciendo las presunciones que permitan al instructor del expediente alcanzar una certeza moral plena sobre la veracidad del consentimiento matrimonial; de no alcanzarse tal certeza sobre la simulación matrimonial, de acuerdo con la presunción general de buena fe y con el carácter fundamental del ius nubendi, el matrimonio deberá autorizarse. Véanse las Instrucciones de 9 de enero de 1995, sobre el expediente previo al matrimonio cuando uno de los contrayentes está domiciliado en el extranjero, y la 31 de enero de 2006 sobre matrimonios de complacencia. 
adecuadas para impedir los abusos en general y la influencia indebida en particular en el ejercicio del ius connubi de las personas con discapacidad.

Por ello, acaso podría cuestionarse no el establecimiento de cautelas que se ha visto no son arbitrarias, sino la naturaleza de las mismas; en este sentido, es bien conocido el rechazo del modelo social de la discapacidad a los dictámenes médicos considerados más propios del modelo médico rehabilitador, de suerte que una propuesta holística sería más conforme con aquel modelo $y$, en este sentido, podría proponerse la necesidad de recabar, en su caso, un informe familiar, social y psicosocial del contrayente. Este informe puede ser recabado hoy por el instructor del expediente a tenor de lo establecido en el art. 58 LRC, pero su carácter preceptivo, sin duda, contribuiría a la normalización del modelo social de la discapacidad.

Las cautelas establecidas para asegurar la validez del consentimiento matrimonial de una persona con discapacidad en el derecho comparado son diversas, identificándose, aún hoy en día, ordenamientos jurídicos que mantienen la discapacidad mental o intelectual como impedimento para contraer matrimonio, si bien la apreciación in concreto de su capacidad natural en la tramitación del expediente permitirá, en su caso, la autorización del matrimonio $^{64}$. Las soluciones comparadas que hemos estudiado son las siguientes:

\section{EL MODELO BELGA: LA AUTORIZACIÓN JUDICIAL PREVIA (DICTAMEN MÉDICO E INFORME SOCIAL)}

El derecho belga recientemente reformado por la Ley de 17 de marzo de 2013, «réformant les régimes d'incapacité et instaurant un nouveau statut de protection conforme à la dignité humaine», establece un sistema basado en la ordonnance que ha de dictar el juez y en la que necesariamente este ha de precisar los actos personales y patrimoniales que la persona protegida no puede realizar en atención a sus circunstancias y estado de salud (art. 492/1 CC). Para facilitar la selección de aquellos actos el legislador belga ha optado por un sistema de check list que enumera una serie de actos personales, de naturaleza civil y de naturaleza médica, íntimamente ligados a la persona y que afectan particularmente a los derechos de la personalidad (intimidad, integridad física,

64 Así, el art. 5 de la Nueva Ley de Matrimonio Civil chilena, núm. 19.947, de 2005, establece, entre otros, que no podrán contraer matrimonio: los que se hallaren privados del uso de razón; los que por un trastorno o anomalía psíquica, fehacientemente diagnosticada, sean incapaces de modo absoluto para formar la comunidad de vida que implica el matrimonio; los que no pudieren expresar claramente su voluntad por cualquier medio, ya sea en forma oral, escrita o por medio de lenguaje de señas. 
consentimiento informado...); si el juez no especifica determinado acto, la regla es la capacidad conservada y, por tanto, la persona puede concluir el acto en cuestión.

Pues bien, en ese listado de actos personales de naturaleza civil se incluye «el consentimiento matrimonial conforme a lo previsto en los arts. 75 y 146 del Código Civil», de suerte que si el juez no extiende la incapacidad al matrimonio, la regla es la capacidad y no hay requisito ulterior; si por el contrario el juez incluye en su selección el consentimiento matrimonial, al tratarse de un acto que no admite ni asistencia ni representación (art. 497/2 CC), se establece una cautela o mecanismo de protección denominado autorisation dérogatoire (Gallus y Van Halteren, 2014: 146-147 y 2016: 68). Esta autorización derogatoria del régimen de incapacidad previsto en la ordonnance que permite a la persona concluir el acto inicialmente prohibido, en aplicación del principio de proporcionalidad y de respeto a la autonomía de la persona con discapacidad, exige, a tenor de lo dispuesto en el art. 145 CC, que el juez de paz valore la capacidad de la persona protegida para expresar su voluntad. Esta autorización derogatoria se ventila por el cauce previsto en el art. 1246 del Code judiciaire que prevé la audiencia de la persona protegida, de su administrador y, en su caso, de su persona de confianza. Asimismo, permite al juez de paz designar un médico experto para que emita opinión sobre el estado de salud de la persona protegida; recabar los informes que resulten útiles y oír a todas las personas que puedan ilustrarle en relación con la solicitud cursada. Por último, puede el juez de paz recabar informes de las personas que cuidan de la persona protegida o que acompañan en el cuidado de la persona protegida y su entorno.

A mi juicio, las cautelas que rodean la autorización del matrimonio de la persona con discapacidad son muy completas, perfectamente alineadas con el modelo social de la discapacidad y, por tanto, plenamente, respetuosas del ius connubi.

\section{EL MODELO FRANCÉS: LA AUTORIZACIÓN DEL MATRIMONIO POR UN TERCERO (AUTORIZACIÓN DEL CURADOR Y, EN SU DEFECTO, DEL JUEZ DE TUTELAS)}

En el derecho francés, se destina un precepto, el art. 460 del CC, a regular las condiciones del matrimonio de la persona protegida, distinguiendo, en función de la medida de protección adoptada, «le mariage d'une personne en curatelle n'est permis qu'avec l'autorisation du curateur ou, à defaut, celle du juge. Le mariage d'une personne en tutelle n'est permis qu'avec l'autorisation du juge ou du Conseil de Famille s'il a été constitué et après l'audition des 
futurs conjoints et recueil, le cas écheant, de l'avis des parents et de l'entourage»; mismos requisitos se exigen para la unión civil registrada (art.461 Cc).

Se comprueba así que en el derecho francés la existencia del consentimiento matrimonial es condición necesaria pero no suficiente, al quedar supeditada la celebración del matrimonio a la obtención de una autorización, del curador o de la autoridad judicial; «esta autorización es la expresión de su consentimiento al matrimonio» (Noguéro y Plazy, 2012: 9). En relación con la vida familiar, la Ley de 5 de marzo de 2007 estableció un régimen diferente para la conclusión de los actos jurídicos relativos a la vida en pareja (matrimonio y pacto civil de solidaridad) y para la de los actos jurídicos relativos a la filiación, a la patria potestad o a la adopción («actes strictement personnels»), para los que el legislador exige tan solo la capacidad natural del sujeto, de suerte que no existe un control previo de la aptitud para consentir el acto; se trata de una presunción iuris tantum de capacidad, que permite la impugnación del acto conforme al art. 414.1 CC (Peterka et al., 2017: 259).

Frente al derecho español (aptitud para prestar el consentimiento) o el derecho belga (capacidad para expresar su voluntad), no se determina en este precepto a qué debe atenerse el curador o el juez de tutelas para autorizar el matrimonio (Raoul Cormeil, 2017: 5). En este sentido, la doctrina especializada señala que al curador le corresponde comprobar que la persona protegida ha meditado su proyecto matrimonial y que está en condiciones de consentir válidamente ante el encargado del Registro Civil; el juez de tutelas, por su parte, debe, imperativamente, oír a los futuros contrayentes y, facultativamente, recabar la opinión de los padres y del entorno. En el trámite de audiencia podrá el juez comprobar que el proyectado matrimonio emana de una voluntad personal, seria y persistente, que la persona protegida está en condiciones de consentir y que el matrimonio es conforme a su interés personal y patrimonial ${ }^{65}$; doctrina y jurisprudencia coinciden, como veremos, en atribuir al matrimonio una naturaleza mixta, al tratarse de un acto personal con importantes conexiones patrimoniales ${ }^{66}$.

La subordinación del consentimiento matrimonial a la obtención de tal autorización ha sido cuestionada ante los tribunales franceses, Cour de Cassation y Conseil Constitutionnel, y, en la actualidad, se encuentra pendiente en el Tribunal Europeo de Derechos Humanos ${ }^{67}$. Efectivamente, la Cour Constitutionnel hubo de resolver una "question prioritaire de constitutionnalité»

65 Véase Raoul-Cormeil (2016: 5-6); Mauclair, (2016: 19); Verheyde, (2012: 464).

66 Véase por todos Peterka et al. (2017: 269).

67 TEDH, Cinquième Section, Requête n. ${ }^{\circ}$ 37646/13, Roger Delecolle c. France. 
a instancias de la Sala Primera de la Cour de Cassation ${ }^{68}$, a fin de determinar la conformidad del art. 460 del Código Civil transcrito a los derechos y libertades garantizados por la Constitución ${ }^{69}$. Esta «question prioritaire de constitutionnalité» se plantea por una persona sometida a curatela, a la que, primero, su curador, argumentando que no está en condiciones de autorizar el matrimonio (por llevar poco tiempo en el cargo), y el juez de tutelas, después, deniegan la autorización exigida para contraer matrimonio válidamente. En el procedimiento, el juez recaba un dictamen médico que concluye que el futuro contrayente presenta un trastorno intelectual, que es capaz de consentir el matrimonio pero que no comprende las consecuencias patrimoniales y financieras de tal unión. Además, se ordena la realización de un informe social para determinar las condiciones, modo de vida y situación del contrayente así como de su entorno, que concluye la existencia de un importante conflicto patrimonial, en el que el interés y bienestar de la persona protegida parece importar poco y que para esta el matrimonio constituye el medio de tener a una persona a su lado que le ayude y organice su vida diaria, evitándole una vida solitaria. Tras oír al contrayente y a su hija, el juez deniega la autorización al considerarla contraria al interés de aquel, que solo busca en el matrimonio evitar una vida solitaria y que la ignorancia de las consecuencias patrimoniales del matrimonio resulta preocupante.

Esta decisión es confirmada por la Cour d'Appel de París, que considera que el matrimonio es un acto importante de la vida civil que compromete la persona y el patrimonio de los contrayentes, de suerte que es indispensable una especial atención no solo que asegure la existencia del consentimiento, sino que, además, compruebe que este se extiende a las consecuencias de tal acto jurídico. Esta decisión se recurre en casación al tiempo que se plantea una "question prioritaire de constitutionnalité». Pues bien, la Cour Constitutionnel, que limita su decisión a la autorización del matrimonio del sometido a curatela, basa su conclusión final, entre otras de carácter más general, sobre dos consideraciones fundamentales:

1) Se atiende a las garantías procesales que rodean la toma de decisión: no se trata de una prohibición general de contraer matrimonio, sino de la obligación de recabar la autorización del curador; en su defecto, esta puede ser suplida por la autorización del juez de tutelas, que adopta una decisión motivada en el seno de un procedimiento contradictorio, que

68 Cour de Cassation, Chambre civile, n. ${ }^{\circ}$ 11-25158.

69 Décision n. ${ }^{\circ}$ 2012-260 QPC, de 29 de junio de 2012. 
puede ser recurrida ante la Cour d'Appel que decide en un procedimiento oral y gratuito.

2) Se atiende a los efectos personales y patrimoniales del matrimonio y, en particular, a su incidencia sobre el régimen de protección: de una parte, su carácter subsidiario respecto de las otras normas tales como las propias del régimen común de representación, de los derechos y deberes conyugales y de los regímenes económico-matrimoniales; y, de otra, el principio adoptado por la Ley de 2007 de Prioridad Familiar. que implica que, adoptada una medida de protección, esta debe ser confiada al cónyuge (art. 449 CC), como una consecuencia del deber de asistencia entre cónyuges (art. 212 CC).

En atención a estas consideraciones, el Conseil Constitutionnel ha considerado que el apdo. primero del art. 460 del Code es conforme a la Constitución:

Considérant qu'eu égard aux obligations personnelles et patrimoniales qui en résultent, le mariage est un acte important de la vie civile; qu'en subordonnant le mariage d'une personne en curatelle à l'autorisation du curateur ou à défaut à celle du juge, le législateur n’a pas privé la liberté du mariage de garanties légales; que les restrictions dont il a accompagné son exercice, afin de protéger les intérêts de la personne, n'ont pas porté à cette liberté une atteinte disproportionnée.

La Cour de Cassation desestima el recurso de casación remitiéndose a esta decisión y a la competencia de la instancia sobre la valoración de los hechos.

A la espera de la decisión del Tribunal Europeo de Derechos Humanos, puede anticiparse nuestra opinión al respecto, plenamente coincidente con el planteamiento del recurrente ${ }^{70}$. Efectivamente, el legislador ha rodeado de garantías la adopción de esta decisión (intervención judicial, resolución motivada y susceptible de recurso) y, naturalmente, el matrimonio tiene incidencia sobre la organización de la protección; pero la cuestión debe, a mi entender,

70 En el fundamento de la «question prioritaire de constitutionnalité» planteada como incidente al recurso de casación se sostenía: «L'article 460 du code civil, qui impose, pour le mariage d'une personne placée sous curatelle, l'autorisation du curateur ou, à défaut, du juge des tutelles, est contraire au principe constitutionnel de la liberté de mariage, acte strictement personnel et privé dont l'exércice doit être garanti toutes les fois où la réalité du consentement du majeur sous curatelle est vérifiée, de sorte qu’il a lieu de transmettre une question prioritaire de constitutionalité au Conseil Constitutionnel». 
plantearse en tales términos: ¿̨debe confiarse a un tercero la conveniencia de celebrarse el matrimonio? Y si fuere así, ¿las contraindicaciones de orden patrimonial deben ser tenidas en cuenta?, ¿no deben medirse la voluntad, los deseos y las preferencias de la persona protegida, su deseo claramente formulado de convivir con la persona elegida y estar acompañado el resto de sus días?

En definitiva, considerar que el matrimonio es un acto de naturaleza mixta con el fin de extender el control del curador o del juez a las consecuencias patrimoniales del matrimonio acaso no sea lo más acertado; limitar el ius nubendi de la persona con discapacidad por consideraciones de naturaleza patrimonial resulta excesivo, toda vez que existen, en el propio sistema de protección, medidas que permiten salvaguardar el patrimonio de la acción del cónyuge, si se revelara necesario. Además, y ello es importante, no debe olvidarse que si la persona está sometida a curatela o a tutela fue porque en su momento se determinó la necesidad de un control patrimonial; luego, naturalmente, en este sentido siempre existirán dificultades para emitir un consentimiento pleno sobre los aspectos patrimoniales del matrimonio. Cuestión distinta sería que esta estuviera sometida a influencia indebida o que no tuviera capacidad para emitir el consentimiento matrimonial que está más cerca de la capacidad natural que de la plena capacidad exigida en el tráfico jurídico patrimonial.

Según el Conseil Constitutionnel, la Cour de Cassation y la doctrina francesa, esta exigencia no constituye una vulneración desproporcionada del ius nubendi $i^{71}$; a mi juicio, toda cautela que no esté dirigida única y exclusivamente a la verificación de una voluntad libremente formada y exteriorizada a través del consentimiento supone una vulneración del derecho a contraer matrimonio sobre la base de un consentimiento pleno y libre de los esposos reconocido en el art. $12 \mathrm{CEDH}$ y en el art. $23 \mathrm{CNY}$. Si la autorización del curador y, en su defecto, la del juez atienden a circunstancias ajenas a la capacidad de consentir y se basan en riesgos de orden patrimonial, acaso la solución no pase por prohibir el matrimonio, sino por articular mecanismos de separación patrimonial o de

71 Prestigiosos especialistas en materia de personas vulnerables, una vez reconocida y valorada la finalidad de la autorización que se dirige a asegurar que el consentimiento es libre, lúcido y meditado, subrayan la incidencia del matrimonio sobre el patrimonio (régimen económico matrimonial, actos de disposición...) y el riesgo económico que implica su celebración «qui peut conduire le protégé à obérer gravement son patrimoine» (Hauser, 2012: 510); desde esta perspectiva de protección y control patrimonial califican la autorización como una restricción benévola, conforme a los principios de protección y necesidad que informan la protección de los mayores vulnerables, y coherente con la naturaleza contractual del matrimonio (Raoul-Cormeil, 2012: 1899); véase asimismo Fresnel (2012: 250-253). 
supervisión de la actividad financiera o del mantenimiento en el cargo del curador $^{72}$. Precisamente a esto se refiere la Convención de Nueva York cuando, en su art. 12, impone a los Estados la adopción de las salvaguardas necesarias para que las personas con discapacidad ejerzan su capacidad jurídica (matrimonio) en igualdad de condiciones con los demás, igualdad que requiriría el mantenimiento tras la celebración del matrimonio de los apoyos previstos en el ámbito patrimonial (control y supervisión del curador).

Trasladar la decisión de contraer matrimonio al curador que aprueba o no el matrimonio, atendiendo a su conformidad con los intereses personales o patrimoniales de la persona con discapacidad, constituye una discriminación por razón de discapacidad prohibida en el art. 2 CNY y una infracción de los arts. 12 y 23 CNY. Si la persona protegida tiene capacidad para formular su voluntad y su deseo de contraer matrimonio, no se puede denegar con base en la importancia del matrimonio y sus implicaciones de orden personal o en los riesgos de naturaleza económica y financiera que se derivan de aquel; se trata de una perspectiva paternalista y de una infantilización de las personas con discapacidad: implica, en definitiva, un régimen de sustitución en la adopción de la decisión más íntima y personal de la vida de las personas, al conceder a un tercero la facultad de impedir la celebración del enlace para proteger, en este caso, el patrimonio de la persona protegida, valorado en seis millones de euros. Constituye una infracción de los principios generales que informan la protección de los mayores vulnerables en el derecho francés y que se recogen en el art. 415 CC: «Cette protection est instaurée et assurée dans le respect des libertés individuelles, des droits fondamentaux et de la dignité de la personne. Elle a pour finalité l'intérêt de la personne protégée. Elle favorise, dans la mesure du posible, l'autonomie de celle-ci ${ }^{73}$.

El legislador está obligado a adoptar las cautelas que permitan verificar la emisión de un consentimiento válido, pero no puede imponer en la esfera personal, por razón de discapacidad, medidas que suplan el mejor interés de la persona con discapacidad (identificado con su voluntad, sus deseos y

72 El art. 447 CC permite al juez, en atención de la situación de la persona protegida y de la entidad de su patrimonio, nombrar varios curadores o tutores para ejercer en común la medida de protección; también permite separar la tutela de la persona y la tutela de los bienes.

73 Con acierto califican de irreconciliables, Noguéro y Plazy (2012: 10), las dos posiciones mantenidas: a) entender que no se vulnera el ius nubendi toda vez que el curatelado conserva la iniciativa de decidir la unión y que el curador sólo está presente para verificar que no se lesionan los intereses de la persona protegida; b) el respeto a las libertades individuales y a los derechos fundamentales impiden la injerencia del curador en una esfera tan íntima. 
preferencias), por la interpretación de un tercero que atiende, como en este caso, a criterios de orden patrimonial y no prioriza la voluntad, los deseos y las preferencias de la persona con discapacidad. Si el matrimonio es un acto personalísimo, no se entiende la subordinación de la existencia de capacidad natural a una aprobación de terceras personas que valoran la conveniencia del matrimonio a la luz de criterios ajenos a la institución matrimonial. Entre tanto recae la decisión del TEDH, a nuestro juicio, en el art. 460 del Code que permite denegar la autorización del matrimonio basándose en circunstancias ajenas al consentimiento matrimonial es discriminatorio y constituye una injerencia desproporcionada en el derecho a contraer matrimonio protegido por el art. $12 \mathrm{CEDH}$ y el art. $23 \mathrm{CNY}$.

\section{EL MODELO ARGENTINO: LA DISPENSA JUDICIAL}

Para adaptar el régimen matrimonial al régimen de salud mental diseñado por la Convención de Nueva York sobre los derechos de las personas con discapacidad, se incluye en el apdo. g) del art. 403 del Código Civil y Comercial, dedicado a los impedimentos dirimentes, "la falta permanente o transitoria de salud mental que le impide tener discernimiento para el acto matrimonial». Este impedimento es dispensable a tenor de lo establecido en el art. 405 que, bajo la rúbrica «Falta de salud mental y dispensa judicial», establece que «en el supuesto del inciso g) del artículo 403 puede contraerse matrimonio previa dispensa judicial». El trámite de autorización requiere, según el citado precepto, solicitud de la persona afectada por la discapacidad mental o intelectual; dictamen de los equipos interdisciplinarios que se pronuncie sobre «la comprensión de las consecuencias jurídicas del acto matrimonial y la aptitud para la vida de relación por parte de la persona afectada»; entrevista personal del juez con los futuros contrayentes; y si el juez lo considera pertinente, se citará a los representantes legales, apoyos y cuidadores a fin de que formulen su opinión al respecto (Iglesias y Krasnow, 2017: 141-144). Se trata, por tanto, de determinar la concurrencia de capacidad natural para concluir el acto matrimonial sobre la base de un consentimiento libre e informado de las consecuencias jurídicas que se siguen del estado matrimonial.

\section{EL MODELO SUIZO: CONTROL DE OFICIO DEL ENCARGADO DEL REGISTRO CIVIL}

En el derecho suizo solo se establece como requisito para contraer matrimonio la mayoría de edad en el art. 94.1. CC. La LF de 19 de diciembre de 2008, de protection de l'adulte, droit de personnes et droit de la Filiation, suprime el inciso segundo de este precepto que sometía el matrimonio del 
interdicto pero capaz de discernimiento a la autorización de su representante legal (art. 94.2 CC); autorización que debía basarse, exclusivamente, en razones compatibles con la configuración constitucional del matrimonio y la asistencia tutelar, tales como los intereses económicos del interdicto o los riesgos que el matrimonio pudiera suponer para su salud mental, física o moral. En la práctica, esta autorización se denegaba raramente ${ }^{74}$. Por ello, el texto actual renuncia a esta disposición, de suerte que una persona sometida a una curatela de alcance general (la versión más invasiva de la protección introducida por la citada reforma), si tiene capacidad de discernimiento, podrá contraer matrimonio sin requisito ulterior (Leuba et al., 2013: 486-487). La capacidad de discernimiento implica que los cónyuges estén en condiciones de comprender el sentido y alcance del compromiso adquirido y su consecuencia inmediata, la constitución de una comunidad de vida.

En el procedimiento preparatorio previo a la celebración del matrimonio, el encargado del Registro deberá verificar que se cumplen las condiciones exigidas para la celebración del matrimonio, en particular la inexistencia de elementos que permitan concluir que la solicitud no responde a la expresión de la libre voluntad de los interesados (art. 100.al.1.3 CC). Si en el momento de la celebración el contrayente fuere incapaz de discernimiento y no lo recupera desde entonces, podrá anularse el matrimonio sobre la base de lo dispuesto en el art. 106 al.2 CC.

\section{CONCLUSIONES}

Pues bien, como conclusión nos parece que las cautelas que rodean la celebración del matrimonio de las personas con discapacidad no deben ser de carácter excepcional, como propone la redacción del nuevo art. 56 CC; lo que es excepcional, y por tanto, de interpretación restrictiva, es la limitación o privación del derecho a contraer matrimonio, de suerte que, como ya señalara la DRGN en el año 1987, el ius nubendi no puede ser desconocido ni menoscabado más que en casos evidentes de falta de capacidad natural y, en caso de duda, han de prevalecer los principios constitucionales del libre desarrollo de la personalidad y del ejercicio de los derechos fundamentales ${ }^{75}$. En la misma línea, la reciente STS de 15 de marzo de 2018 defiende «que la consideración del matrimonio como derecho humano derivado de la dignidad de la persona

74 Message concernant la révision du Code civil suisse, 28 juin 2006 (06.063).

75 En este sentido, véase Marín López (2009:178). 
y manifestación del libre desarrollo de la personalidad... deben inclinar a reforzar el principio favor matrimonii».

Esta interpretación nos lleva a rechazar las fórmulas prohibitivas utilizadas en tiempos pretéritos y que aún conservan algunos Códigos Civiles y la propuesta del legislador francés que subordina el matrimonio a la conveniencia de su celebración apreciada por el curador o, en su defecto, el juez de tutelas.

\section{Bibliografía}

Aguilera Rull, A. (2017). Edad núbil y consentimiento matrimonial. En T. F. Torres García (dir). Construyendo la igualdad: la feminización del derecho privado (pp. 371-397). Valencia: Tirant lo Blanc.

Alvárez Lata, N. y Seoane Rodríguez, J. A. (2010). El proceso de toma de decisiones de la persona con discapacidad. Una revisión de los modelos de representación y guarda a la luz de la Convención sobre los Derechos de las personas con discapacidad. Derecho Privado y Constitución, 24, 11-66.

Bariffi, F. (2014). El régimen jurídico internacional de la capacidad jurídica de las personas con discapacidad. Madrid: Cinca.

Campuzano Tomé, H. (2010). Comentario al artículo 56. En A. Domínguez Luelmo (dir). Comentarios al Código civil (pp. 164-165). Valladolid: Lexnova.

De Amunátegui Rodríguez, C. (2017). Las parejas no casadas. En M. Yzquierdo Tolsada y M. Cuena Casas (dirs). Tratado de Derecho de la Familia, IV (pp. 8491047). Cizur Menor: Thomson Reuters Aranzadi.

De Asís Roig, R. (2013). Sobre discapacidad y derechos. Madrid: Dykinson.

De Castro y Bravo, F. (1984). Derecho civil de España, II. Madrid: Civitas.

De Pablo Contreras, P. (2011) Matrimonio civil y Sistema matrimonial. En M. Yzquierdo Tolsada y M. Cuena Casas (dirs). Tratado de Derecho de la Familia, I, (pp. 427-538). Cizur Menor: Thomson Reuters Aranzadi.

Díaz Martínez, A. (2013). Comentario al artículo 56. En R. Bercovitz Rodríguez-Cano (dir). Comentarios al Código civil, I, (pp. 713-721). Valencia: Tirant lo Blanc.

Fresnel, F. (2012). La triade: le majeur protégé, la mesure de protection et le mariage. Paradis, purgatoire ou enfer? Actualité Juridique Famille, 6, 250-253.

Frison-Roche, M. A. (1995). Remarques sur la distinction de la volonté et du consentement en droits de contrats. Revue Trimestrielle de Droit civil, 3, 573-578.

Gallus, N. y Van Alteren, Th. (2014). Le nouveau régime de protection des majeurs. Bruxelles: Bruylant.

Gallus, N. y Van Alteren, Th. (2016). La personnalisation des mesures d'incapacité. En N. Dandoy (dir). La protection des personnes majeures (pp. 9-70). Bruxelles: Larcier.

García Herrera, V. (2015). Los matrimonios de conveniencia. Madrid: Universidad Rey Juan Carlos. 
Gete-Alonso Calera, M. C. (1984). Comentario al artículo 73. En Comentarios a las Reformas de Derecho de Familia, I, (pp. 359-389). Madrid: Tecnos.

Hauser, J. (2012). Chroniques Personnes et Droits de la Famille. Revue Trimestrielle de Droit civil, 3, 502-524.

Iglesias, M. B. y Krasnow, A. N. (2017). Derecho de las Familias y las Sucesiones. Buenos Aires: Thomson Reuters La Ley.

Leuba, A., Stettler, M., Buchler A. y Hafeli, C. (2013). Protection de l'adulte, Commentaire du Droit de la Famille. Berna: Stampfli Editions.

Marin López, M. J. (2009) Comentario al artículo 56. En R. Bercovitz Rodríguez-Cano (dir). Comentarios al Código Civil (pp. 177-178). Cizur Menor: Aranzadi Thomson Reuters.

Martínez de Aguirre, C. (2014). El tratamiento jurídico de la discapacidad psíquica: reflexiones para una reforma legal. Cizur Menor: Thomson Reuters Aranzadi.

Mauclair S. (2016). Du consentement au mariage d'un incapable. Revue Juridique Personnes et Famille, 2, 19-20.

Noguéro, D. y Plazy, J. M. (2012). Majeurs Protégés (Juillet 2011-Juin 2012). Recueil Dalloz, 40, 2699.

Palacios, A. (2008). El modelo social de la discapacidad. Madrid: Cermi.

Peterka, N., Caron-Déglise, A. y Arbellot, F. (2017). Protection de la personne vulnérable. Paris: Dalloz.

Puig Ferriol, L. (1984). Comentario al artículo 56. En Comentarios a las reformas de Derecho de Familia, I, (pp. 249-257). Madrid: Tecnos.

Raoul-Cormeil, G. (2012). L'autorisation requise pour le mariage du curatélaire, sage précaution dans l'exercice de la liberté nuptiale. Recueil Dalloz, 29, 1899.

_ (2016). Le caractère attitré de la demande d'autorisation à mariage de la personne protégée. Recueil Dalloz, 15, 875.

— (2017). Défaut de consentement et défaut d'autorisation à mariage. Recueil Dalloz, 33, 1967.

Salvador Coderch, P. (1984). Comentario al artículo 44. En Comentarios a las Reformas de Derecho de Familia, I, (pp. 118-1309). Madrid: Tecnos.

Serrano Gómez, E. (2011). La celebración del matrimonio. M. Yzquierdo Tolsada y M. Cuena Casas (dirs). Tratado de Derecho de la Familia, I, (pp. 539-639). Cizur Menor: Thomson Reuters Aranzadi.

Verheyde, T. (2012). Mariage du majeur en curatelle: décision fondamentale du Conseil Constitutionnel pour l'avenir de la protection juridique des majeurs. Actualité Juridique Famille, 9, 463-466. 